\title{
Scenario-Based Stochastic Framework for Optimal Planning of Distribution Systems Including Renewable-Based DG Units
}

\author{
Ashraf Ramadan ${ }^{1}$, Mohamed Ebeed ${ }^{2}$ D, Salah Kamel ${ }^{1}$ (D), Almoataz Y. Abdelaziz ${ }^{3}$ and Hassan Haes Alhelou ${ }^{4, *}$ \\ 1 Department of Electrical Engineering, Faculty of Engineering, Aswan University, Aswan 81542, Egypt; \\ ashraframadanragab@gmail.com (A.R.); skamel@aswu.edu.eg (S.K.) \\ 2 Department of Electrical Engineering, Faculty of Engineering, Sohag University, Sohag 82524, Egypt; \\ mebeed@eng.sohag.edu.eg \\ 3 Department of Electrical Engineering, Faculty of Engineering and Technology, Future University \\ in Egypt, Cairo 11835, Egypt; almoataz.abdelaziz@fue.edu.eg \\ 4 School of Electrical and Electronic Engineering, University College Dublin (UCD), Dublin 4, Ireland \\ * Correspondence: hassan.haesalhelou@ucd.ie
}

check for updates

Citation: Ramadan, A.; Ebeed, M.; Kamel, S.; Abdelaziz, A.Y.; Haes Alhelou, H. Scenario-Based Stochastic Framework for Optimal Planning of Distribution Systems Including Renewable-Based DG Units. Sustainability 2021, 13, 3566. https://doi.org/10.3390/su13063566

Academic Editor:

Alberto-Jesus Perea-Moreno

Received: 2 March 2021

Accepted: 17 March 2021

Published: 23 March 2021

Publisher's Note: MDPI stays neutral with regard to jurisdictional claims in published maps and institutional affiliations.

Copyright: (c) 2021 by the authors. Licensee MDPI, Basel, Switzerland. This article is an open access article distributed under the terms and conditions of the Creative Commons Attribution (CC BY) license (https:// creativecommons.org/licenses/by/ $4.0 /)$.

\begin{abstract}
Renewable energy-based distributed generators are widely embedded into distribution systems for several economical, technical, and environmental tasks. The main concern related to the renewable-based distributed generators, especially photovoltaic and wind turbine generators, is the continuous variations in their output powers due to variations in solar irradiance and wind speed, which leads to uncertainties in the power system. Therefore, the uncertainties of these resources should be considered for feasible planning. The main innovation of this paper is that it proposes an efficient stochastic framework for the optimal planning of distribution systems with optimal inclusion of renewable-based distributed generators, considering the uncertainties of load demands and the output powers of the distributed generators. The proposed stochastic framework depends upon the scenario-based method for modeling the uncertainties in distribution systems. In this framework, a multi-objective function is considered for optimal planning, including minimization of the expected total power loss, the total system voltage deviation, the total cost, and the total emissions, in addition to enhancing the expected total voltage stability. A novel efficient technique known as the Equilibrium Optimizer (EO) is actualized to appoint the ratings and locations of renewable-based distributed generators. The effectiveness of the proposed strategy is applied on an IEEE 69-bus network and a 94-bus practical distribution system situated in Portugal. The simulations verify the feasibility of the framework for optimal power planning. Additionally, the results show that the optimal integration of the photovoltaic and wind turbine generators using the proposed method leads to a reduction in the expected power losses, voltage deviations, cost, and emission rate and enhances the voltage stability by $60.95 \%, 37.09 \%, 2.91 \%, 70.66 \%$, and $48.73 \%$, respectively, in the 69-bus system, while in the 94-bus system these values are enhanced to be $48.38 \%, 39.73 \%, 57.06 \%$, $76.42 \%$, and $11.99 \%$, respectively.
\end{abstract}

Keywords: renewable energy; uncertainties; distributed generators; wind turbine; solar photovoltaic; equilibrium optimizer; radial distribution system; scenario-based method

\section{Introduction}

\subsection{Problem Statement}

Uncertainty is essential in the optimal power planning problem of electrical systems, and it is a main consideration adding to its complexity, specifically the uncertainties of the renewable energy resources (RERs) and load demands. Many research efforts related to the optimal integration of Distributed Generators (DGs) are expressed as ideal optimization problems, and only few have considered uncertainty. The optimal allocation of the photovoltaic (PV) and wind turbine (WT) units in power systems and techniques existing in the literature considering the uncertainty of systems have an incredible impact 
on the planning of renewable DGs, and uncertainties effect the load demand and the output powers of solar and wind-based DGs in the distribution systems (DSs). The contribution and the research gap are referenced in detail. Electric power generation organizations will in general utilize (DGs) near the load to convey the electrical power to the consumers for technical, economic, and environmental reasons. As of late, integration of the RERs including wind and photovoltaic energies have become a favored solution for defeat increasing the load growth as they are sustainable and clean resources. Nonetheless, the inclusion of the RERs in the distribution grids face numerous issues due to their intermittency and the fluctuations of the output power, which increases the uncertainties in electrical systems. In this way, the uncertainties in power systems should be taken into consideration for correct planning and the secure operation of power systems.

\subsection{Literature Survey}

The essential purpose of efficient planning in distribution systems is to provide excellent solutions that guarantee the security, quality, and reliability of power supply to clients at the least cost [1]. The cost of power generation from conventional generators is expanding quickly because of the increase in fuel costs, although lately the generation cost of RERs has diminished. Alongside financial contemplations, another advantage of RERs is the eco-friendly power generation from these sources [2]. A stochastic scenario modeling of a multistage joint for the distribution systems planning has been utilized to decrease the operational and investment costs [3]. Sensible application of DGs can bring numerous points of interest, for example, voltage profile improvement, reducing emissions and energy cost [4-6].

Nonetheless, improper placement of DGs may lead to the fluctuations of voltage and also system instability because of the uncertain nature of RERs $[7,8]$. The issue of optimal integration of DGs has been explored in the several papers from different points of view. The authors in [9] suggested an improved adaptive genetic algorithm for resolving the optimal DG allocation problem. In [10], an efficient framework has been suggested for the optimal DG allocation problem to reduce the system costs. The authors in [11] offered a genetic algorithm along with the Monte Carlo method for solving the optimal DG integration problem under the uncertainties of RER generation. The cost of energy losses and DGs have been considered in the model. In [12], an efficient method has been presented for the optimal planning of accommodating the integration of PEV along with renewable DGs under uncertainties of the system. In [13], the optimal power planning problem in the active distribution system is solved to reduce total cost and emissions using a cuckoo search (CS) with optimal integration of WTs and demand response, considering the uncertainties of the system by the scenario synthesis method. The authors in [14] applied the Crisscross Optimization Algorithm and Monte Carlo Simulation for assigning the rating and location of DGs in the distribution system for reducing the power losses and the cost. Esmaeili et al. presented a multi-objective framework for optimizing the DG allocation and reconfiguration of the distribution network using the Big Bang-Big Crunch algorithm [15]. In [16], a probabilistic planning method was suggested based on mixed integer nonlinear programming (MINLP) and has been implemented to assign energy loss reduction with optimal integration of RERs in a rural distribution system. The author in [17] proposed a stochastic model for optimizing the investment of the DGs under uncertain conditions in distribution networks. Ref. [18] proposed a planning strategy for a hybrid solar-wind generation MG system with hydrogen energy storage using a novel multi-objective optimization algorithm to minimize the following three objective functions: loss of load expected, annualized cost of the system, and loss of energy expected. Ref. [19] proposed an algorithm for DG allocation planning based on using the probabilistic uncertainty modeling method. Several optimization algorithms have been used to determine the best size and location of DGs in a radial distribution network (RDN) considering the uncertainties of systems such as Particle Swarm Optimization (PSO) [20], modified sine cosine algorithm [21], Cuckoo Search Algorithm (CA) [22], water 
cycle algorithm [23], Improved Antlion Optimization Algorithm (IALO) [24], Specialized Genetic Algorithm (SGA) [25], Ant Colony Optimizer (ACO) [26], Modified Differential Evolution Algorithm (MDEA) [27], harmony search algorithm [28], Seeker Optimization Algorithm (SOA) [29], and teaching learning-based optimization [30].

The Equilibrium Optimizer (EO) is a novel physical-based optimization technique which emulates the control volume mass balance models [31]. The EO has been applied for solving numerous engineering problems, and in [32] it has been applied for solving the economic dispatch of a micro-grid The authors in [33] applied the EO for assigning the optimal rating and locations of the renewable-based DGs for loss reduction under uncertainties of the system. In [34], the EO was implemented for optimizing the structural design of vehicle components. The $\mathrm{EO}$ was employed for solving the optimal power flow problem in an AC/DC network. The solar photovoltaic parameters have been estimated using the $\mathrm{EO}$ in [35].

In this paper, the EO is utilized for deciding the best allocation of the solar and wind units for minimization of the expected power losses, the system voltage deviation, the total cost, and the total emissions as well as enhancing the expected voltage stability considering the uncertainties of load demands and solar and wind power generators in an IEEE 69-bus network and a 94-bus practical distribution system situated in Portugal.

\subsection{Contribution of Paper}

From the previous survey, the main concern or the problem statement related to the optimal planning of distribution systems with the inclusion of optimal RERs is the uncertainties of load demand and the output power of the RERs. Therefore, the planning problem became more complex and needs an efficient method to be solved.

This paper contributes to the existing body of knowledge as it solves the optimal planning problem in a distribution system for optimal incorporation of DGs using a scenario-based stochastic framework considering the uncertainties of load demands and the output powers of RERs. The innovation and contributions of this paper are summarized as follows:

- Proposing an efficient framework for the optimal planning of distribution systems considering the uncertainties of load and the output powers of renewable based DGs.

- The application of scenario-based methods for modeling the uncertainties in the electrical systems.

- The application of an efficient algorithm, called the EO, for solving the planning problem.

- The developed algorithms are applied for optimal integration of the renewable-based DGs for loss reduction, voltage improvements, system voltage deviation, the total cost, and the total emissions of the IEEE 69-bus and 94-bus distribution networks.

- A comparison is presented between the EO and other well know techniques for solving the planning problem.

\subsection{Paper Layout}

The paper is arranged as follows: Section 2 displays the problem formulation including the objective function. Section 3 illustrates the uncertainty modeling methods. Section 4 introduces an overview of the EO technique. Section 5 shows the obtained outcomes, while Section 6 lists the paper's conclusions.

\section{Problem Formulation}

In this study, five objective functions are considered in a multi-objective function. It is worth mentioning that in case of modeling or considering the uncertainties in power systems, a set of scenarios will be generated. Thus, these scenarios should be considered for the efficient solving of planning problems, and each scenario has its expected values as depicted in the following sections. In this work, the considered objective function is 
a multi-objective function comprising five objective functions which can be presented as follows:

\subsection{The Objective Functions}

2.1.1. Minimization of the Expected Power Loss $\left(E P_{\text {Loss }}\right)$

The expected power losses of the radial distribution network are determined as follows:

$$
P_{l o s s(k, k+1)}=R_{k, k+1}\left(\frac{P_{k}^{2}+j Q_{k}^{2}}{\left|V_{k}\right|^{2}}\right)
$$

where

$$
\begin{aligned}
& P_{\text {Total_Loss }}=\sum_{i=1}^{N T} P_{\text {Loss }, i} \\
& E T P_{\text {Loss }}=\sum_{k=1}^{N s} E P_{\text {Loss }, k}=\sum_{k=1}^{N s} \pi_{S, k} \times P_{\text {Total }} \text { Loss }, k
\end{aligned}
$$

2.1.2. Minimization of the Expected Voltage Deviations (ETVD)

The expected summation of the voltage deviations of the radial distribution network are given as follows:

$$
E T V D=\sum_{k=1}^{N s} E V D_{k}=\sum_{k=1}^{N s} \pi_{s, k} \times V D_{k}
$$

where

$$
V D=\sum_{n=1}^{N B}\left|V_{n}-1\right|
$$

2.1.3. Enhancement of the Expected Voltage Stability (ETVSI)

The expected summation of the voltage stability indices can be expressed as follows:

$$
E T V S I=\sum_{k=1}^{N s} E V S I_{k}=\sum_{k=1}^{N s} \pi_{S, k} \times V S I_{k}
$$

where

$$
V S I_{n}=\left|V_{n}\right|^{4}-4\left(P_{n} X_{n m}-Q_{n} R_{n m}\right)^{2}-4\left(P_{n} X_{n m}+Q_{n} R_{n m}\right)\left|V_{n}\right|^{2}
$$

2.1.4. Minimization of the Expected Total Cost (ETCost)

The expected total annual cost (ETCost) is considered, which consists of the expected annual energy loss cost $\left(E \operatorname{Cost}_{\text {loss }}\right)$, the expected cost of the electric energy savings from the main substation $\left(E \operatorname{Cost}_{G r i d}\right)$, the expected PV units cost $\left(E \operatorname{Cost}_{P V}\right)$, and the expected WT cost $\left(E^{C o s t}{ }_{W T}\right)$. It can be represented as follows:

$$
E T \operatorname{Cos} t=E \operatorname{Cost}_{\text {loss }}+E \operatorname{Cost}_{\text {Grid }}+E \operatorname{Cost}_{P V}+E \operatorname{Cost}_{W T}
$$

The items detailed in Equation (8) are defined as follows:

$$
\begin{gathered}
\operatorname{Cost}_{\text {Grid }}=8760 \times K_{\text {Grid }} \times P_{\text {Grid }} \\
\text { ETCost }_{\text {Grid }}=\sum_{k=1}^{N s} \operatorname{ECost}_{\text {Grid }, k}=\sum_{k=1}^{N s} \pi_{S, k} \times \operatorname{Cost}_{\text {Grid }, k} \\
\text { Cost }_{\text {Loss }}=8760 \times K_{\text {Loss }} \times P_{\text {Total_loss }} \\
\text { ETCost }_{\text {Loss }}=\sum_{k=1}^{N s} \text { ECost }_{\text {Loss }, k}=\sum_{k=1}^{N s} \pi_{S, k} \times \operatorname{Cost}_{\text {Loss }, k}
\end{gathered}
$$




$$
\begin{gathered}
\text { ETCost }_{\text {wind }}=\sum_{k=1}^{N s} E \operatorname{Cost}_{\text {wind }, k}=\sum_{k=1}^{N s} \pi_{S, k} \times\left(a_{1}+8760 \times b_{1} \times P_{W T, k}\right) \\
a_{1}=C F \times C S D G_{W T} \times P_{w r} \\
b_{1}=\text { Cost_W }_{-} T_{O \& M}+\text { Cost_WT } T_{\text {Fuel }} \\
C F=\frac{\rho \times(1+\rho)^{N P}}{(1+\rho)^{N P}-1}
\end{gathered}
$$

where $a_{1}$ is the annual installment of the wind turbine, and $b_{1}$ is the annual operation and maintenance cost of the wind turbine.

$$
\begin{gathered}
\operatorname{ETCost}_{P V}=\sum_{k=1}^{N s} E \operatorname{Cost}_{P V, k}=\sum_{n=1}^{N s} \pi_{S, k} \times\left(a_{2}+8760 \times b_{2} \times P_{P V, k}\right) \\
a_{2}=C F \times C S D G_{P V} \times P_{s r} \\
b_{2}=\text { Cost_PV }_{O} \& M+\text { Cost_PV }_{\text {Fuel }}
\end{gathered}
$$

where $a_{2}$ is the annual installment of the PV unit, and $b_{2}$ is the annual operation and maintenance cost of the PV unit. In this paper the cost coefficients of PV are selected to be $C S D G_{P V}=770 \mathrm{USD} / \mathrm{kW}$, Cost_PV $V_{O \& M}=0.01 \mathrm{USD} / \mathrm{kWh}$, Cost_PV $_{-} V_{\text {Fuel }}=0 \mathrm{USD} / \mathrm{kWh}$, and the cost coefficients of the wind are selected to be $C S D G_{W T}=4000 \mathrm{USD} / \mathrm{kW}$, Cost_WT $T_{O \& M}=0.01 \mathrm{USD} / \mathrm{kWh}$, Cost_WT $_{\text {Fuel }}=0 \mathrm{USD} / \mathrm{kWh}[36]$.

\subsubsection{Minimization of the Expected Total Emissions (ETEmission)}

The expected total annual emissions in kilotons $(\mathrm{Kt})$ can be expressed as follows:

$$
\text { ETEmission }=\sum_{k=1}^{N s} \text { EEmission }_{k}=\sum_{n=1}^{N s} \pi_{S, k} \times P_{\text {Grid, } k} \times L F \times E R_{\text {Grid }} \times 8760
$$

According to $E R_{G r i d}$, the emission rate of grid values of $\mathrm{NOx}, \mathrm{CO}_{2}$, and $\mathrm{SO}_{2}$ are $2.2952 \mathrm{~kg} / \mathrm{MWh}, 921.25 \mathrm{~kg} / \mathrm{MWh}$ and $3.5834 \mathrm{~kg} / \mathrm{MWh}$, respectively [15].

\subsubsection{The Multi-Objective Function}

In this work, the previous objective functions are considered simultaneously. To consider these objective functions concurrently, the weight approach method is utilized. In addition, the objectives should be normalized as follows via division by its base value (without PV or WT), which makes the objective function dimensionless and also prevents any scaling problems. The augmented objective function can be described as follows:

$$
F=\propto_{1} F_{1}+\propto_{2} F_{2}+\alpha_{3} F_{3}+\propto_{4} F_{4}+\propto_{5} F_{5}
$$

where $\alpha_{1}, \alpha_{2}, \alpha_{3}, \alpha_{4}$, and $\alpha_{5}$ are weighting factors. The summation of weight factors should equal 1 as follows:

$$
\left|\alpha_{1}\right|+\left|\alpha_{2}\right|+\left|\alpha_{3}\right|+\left|\alpha_{4}\right|+\left|\alpha_{5}\right|=1
$$

The normalized objective functions can be formulated as follows:

$$
\begin{gathered}
F_{1}=\frac{E T P_{\text {Loss }}}{E T P_{\text {Loss }_{\text {base }}}} \\
F_{3}=\frac{E T V D}{E T V D_{\text {base }}} \\
F_{3}=\frac{1}{E T V S I}
\end{gathered}
$$




$$
\begin{aligned}
& F_{4}=\frac{E T \operatorname{Cos} t}{\text { ETCost }_{\text {base }}} \\
& F_{5}=\frac{\text { ETEmission }_{\text {ETEmission }}^{\text {base }}}{\text { ETE }}
\end{aligned}
$$

\subsection{The System Constraints}

The system constraints are categorized as follows:

2.2.1. Equality Constraints

$$
\begin{gathered}
P_{\text {Grid }}+\sum_{i=1}^{N P V} P_{P V, i}+\sum_{i=1}^{N W T} P_{W T, i}=\sum_{i=1}^{N T} P_{\text {loss }, i}+\sum_{i=1}^{N B} P_{L, i} \\
Q_{\text {Grid }}+\sum_{i=1}^{N T} Q_{W T, i}=\sum_{i=1}^{N T} Q_{\text {loss }, i}+\sum_{i=1}^{N B} Q_{L, i}
\end{gathered}
$$

2.2.2. Inequality Constraints

$$
\begin{gathered}
V_{\text {min }} \leq V_{i} \leq V_{\text {max }} \\
\sum_{i=1}^{N W T} Q_{W T, i} \leq \sum_{i=1}^{N B} Q_{L, i} \\
I_{n} \leq I_{\max , n} n=1,2,3 \ldots, N T
\end{gathered}
$$

\section{Uncertainty Modeling}

In this work, the uncertainties that existed in the power system are considered by solving the problem of optimal power planning. The proposed stochastic framework considered three uncertain parameters including load demand, solar irradiance, and wind speed. The continuous probability density functions (PDFs) of wind speed, solar irradiance, and loads are used for representing the uncertainties of these parameters; then, the scenariobased method is utilized for generating a set of scenarios from combinations of these parameters. The proposed stochastic framework can be depicted as follows:

\subsection{Modeling of Load Demand}

The normal PDF $\left(f_{d}\left(P_{d}\right)\right)$ is used for uncertainty representation of the load demand, which can be described using the following equations [37]:

$$
f_{d}\left(P_{d}\right)=\frac{1}{\sigma_{d} \sqrt{2 \pi}} \exp \left[-\frac{\left(P_{d}-\mu_{d}\right)^{2}}{2 \sigma_{d}{ }^{2}}\right]
$$

The generated load scenarios and their probabilities obtained from (33) can be obtained as follows [38]:

$$
\begin{gathered}
\pi_{d, i}=\int_{P_{d, i}^{\min }}^{P_{d, i}^{\max }} \frac{1}{\sigma_{d} \sqrt{2 \pi}} \exp \left[-\frac{\left(P_{d}-\mu_{d}\right)^{2}}{2 \sigma_{d}^{2}}\right] d P_{d} \\
P_{d, i}=\frac{1}{\tau_{d, i}} \int_{P_{d, i}^{\min }}^{P_{d, i}^{\max }} \frac{P_{d}}{\sigma_{d} \sqrt{2 \pi}} \exp \left[-\frac{\left(P_{d}-\mu_{d}\right)^{2}}{2 \sigma_{d}^{2}}\right] d P_{d}
\end{gathered}
$$

In this work, three load scenarios are presented. The load scenarios are obtained by dividing the normal PDF into three intervals. Table 1 provides the load scenarios and their probabilities when $\mu_{d}$ and $\sigma_{d}$ are 70 and 10 [39]. 
Table 1. The generated scenarios of the uncertain parameters.

\begin{tabular}{ccc}
\hline Load Scenario & $\pi_{d, i}$ & Loading $\%$ \\
\hline 1 & 0.1587 & 54.7486 \\
2 & 0.6827 & 70.0000 \\
3 & 0.1587 & 85.2514 \\
\hline Wind Scenario & $\pi_{w i n d, z}$ & Wind Speed $(\mathrm{m} / \mathrm{s})$ \\
\hline 1 & 0.7902 & 7.4518 \\
2 & 0.1694 & 13.6153 \\
3 & 0.0404 & 17.7289 \\
\hline Irradiance Scenario & $\pi_{\text {Solar }, m}$ & Solar Irradiance $\left(\mathrm{W} / \mathrm{m}^{2}\right)$ \\
\hline 1 & 0.1605 & 416.0627 \\
3 & 0.4412 & 609.1166 \\
\hline
\end{tabular}

\subsection{Modeling of Wind Speed}

The Weibull PDFs $\left(f_{v}(v)\right)$ are used to describe the uncertainties of wind speed which can be expressed as follows [38]:

$$
f_{v}(v)=\left(\frac{k}{c}\right)\left(\frac{k}{c}\right)^{(k-1)} e^{-(v / c)^{k}} 0 \leq v<\infty
$$

The wind turbine output power can be specified as follows [40,41]:

$$
P_{w}\left(v_{\omega}\right)=\left\{\begin{array}{ccc}
0 & \text { for } & v_{\omega}<v_{\omega i} \& v_{\omega}>v_{\omega o} \\
P_{w r}\left(\frac{v_{\omega 0}-v_{\omega i}}{v_{\omega r}-v_{\omega i}}\right) & \text { for } & \left(v_{\omega i} \leq v_{\omega} \leq v_{\omega r}\right) \\
P_{w r} & \text { for } & \left(v_{\omega r}<v_{\omega} \leq v_{\omega o}\right)
\end{array}\right.
$$

Additionally, a set of scenarios can be obtained from (36) by dividing the $f_{v}(v)$ into of a set of wind speed intervals. The generated wind speeds and their probabilities can be obtained as follows [42]:

$$
\begin{gathered}
\pi_{\text {wind }, z}=\int_{v_{z}^{\min }}^{v_{z}^{\max }}\left(\left(\frac{k}{c}\right)\left(\frac{k}{c}\right)^{(k-1)} e^{-(v / c)^{z}}\right) d v \\
v_{z}=\frac{1}{\pi_{w i n d, z}} \int_{v_{z}^{\min }}^{v^{\max }}\left(\left(\frac{k}{c}\right)\left(\frac{k}{c}\right)^{(z-1)} e^{-(v / c)^{z}}\right) d v
\end{gathered}
$$

In this paper, three scenarios of wind speed are generated from the previous equations. The wind speed scenarios and their probabilities are listed in Table 1 in the case of selecting $c$ and $k$ to be 10.0434 and 2.5034, respectively, as given in [38].

\subsection{Modeling of Solar Irradiance}

The Beta PDF is used to specify the uncertainty of the solar irradiance, which can be given as follows [43]:

$$
\begin{gathered}
f_{G}(G)=\left\{\begin{array}{c}
\frac{\Gamma(\alpha+\beta)}{\Gamma(\alpha)+\Gamma(\beta)} \times G^{\alpha-1} \\
\times(1-G)^{\beta-1} \\
\text { 0otherwise }
\end{array} \text { If } 0 \leq G \leq 1,0 \leq \alpha, \beta\right. \\
\beta=\left(1-\mu_{s}\right) \times\left(\frac{\mu_{s} \times\left(1+\mu_{s}\right)}{\sigma_{s}^{2}}\right)-1 \\
\sigma_{s}=\left(1-\mu_{s}\right) \times\left(\frac{\mu_{s} \times \beta}{\left(1-\mu_{s}\right)}\right)-1
\end{gathered}
$$


The yield power from the PV system can be calculated as follows [44,45]:

$$
P_{s}(G)=\left\{\begin{array}{c}
P_{s r}\left(\frac{G^{2}}{G_{s t d} \times X_{c}}\right) \text { for } 0<G \leq X_{c} \\
P_{s r}\left(\frac{G}{G_{s t d}}\right) \text { for } G \geq X_{c}
\end{array}\right.
$$

In the previous equation, $G_{s t d}$ is set to be $1000 \mathrm{~W} / \mathrm{m}^{2}$, and $X_{c}$ is a certain irradiance point is set to be $120 \mathrm{~W} / \mathrm{m}^{2}$ [41]. Three scenarios can be obtained from the previous equations by dividing the PDF into three intervals. The portability of solar irradiance and its corresponding solar irradiance for each scenario are given as follows [42]:

$$
\begin{gathered}
\pi_{\text {Solar }, m}=\int_{G_{m}^{\min }}^{G_{m}^{\max }} f_{G}(G) d G \\
G_{m}=\frac{1}{\pi_{\text {Solar }, m}} \int_{G_{m}^{\min }}^{G_{m}^{\text {min }}}\left(\frac{\Gamma(\alpha+\beta)}{\Gamma(\alpha) \cdot \Gamma(\beta)} \times\left(G^{\alpha-1}\right) \times(1-G)^{\beta-1}\right) d G
\end{gathered}
$$

The generated scenarios of the solar irradiance and their probabilities are listed in Table 1 in the case of selecting $\alpha$ and $\beta$ to be 6.38 and 3.43, respectively, as given in [38].

\subsection{The Combined Load-Generation Model}

To consider the uncertainties of the load demand, wind speed, and irradiance simultaneously, the probabilities of these parameters depicted in (34), (38), and (44) are multiplied together according to (46) as follows:

$$
\pi_{S}=\pi_{d, i} \times \pi_{w i n d, k} \times \pi_{\text {Solar }, m}
$$

\begin{tabular}{|c|c|c|c|c|c|c|c|}
\hline Scenario & Loading \% & Wind Speed $(\mathrm{m} / \mathrm{s})$ & Solar Irradiance $\left(\mathrm{W} / \mathrm{m}^{2}\right)$ & $\pi_{d, i}$ & $\pi_{\text {Solar }, m}$ & $\pi_{\text {wind }, z}$ & $\pi_{S}$ \\
\hline S1 & 54.7486 & 7.4518 & 416.0627 & 0.1587 & 0.1605 & 0.7902 & 0.0201 \\
\hline S2 & 54.7486 & 13.6153 & 416.0627 & 0.1587 & 0.1605 & 0.1694 & 0.0043 \\
\hline S3 & 54.7486 & 17.7289 & 416.0627 & 0.1587 & 0.1605 & 0.0404 & 0.0010 \\
\hline S4 & 54.7486 & 7.4518 & 609.1166 & 0.1587 & 0.4412 & 0.7902 & 0.0553 \\
\hline S5 & 54.7486 & 13.6153 & 609.1166 & 0.1587 & 0.4412 & 0.1694 & 0.0119 \\
\hline S6 & 54.7486 & 17.7289 & 609.1166 & 0.1587 & 0.4412 & 0.0404 & 0.0028 \\
\hline S7 & 54.7486 & 7.4518 & 790.4621 & 0.1587 & 0.3983 & 0.7902 & 0.0499 \\
\hline S8 & 54.7486 & 13.6153 & 790.4621 & 0.1587 & 0.3983 & 0.1694 & 0.0107 \\
\hline S9 & 54.7486 & 17.7289 & 790.4621 & 0.1587 & 0.3983 & 0.0404 & 0.0026 \\
\hline S10 & 70.0000 & 7.4518 & 416.0627 & 0.6827 & 0.1605 & 0.7902 & 0.0866 \\
\hline S11 & 70.0000 & 13.6153 & 416.0627 & 0.6827 & 0.1605 & 0.1694 & 0.0186 \\
\hline $\mathrm{S} 12$ & 70.0000 & 17.7289 & 416.0627 & 0.6827 & 0.1605 & 0.0404 & 0.0044 \\
\hline $\mathrm{S} 13$ & 70.0000 & 7.4518 & 609.1166 & 0.6827 & 0.4412 & 0.7902 & 0.2380 \\
\hline S14 & 70.0000 & 13.6153 & 609.1166 & 0.6827 & 0.4412 & 0.1694 & 0.0510 \\
\hline S15 & 70.0000 & 17.7289 & 609.1166 & 0.6827 & 0.4412 & 0.0404 & 0.0122 \\
\hline S16 & 70.0000 & 7.4518 & 790.4621 & 0.6827 & 0.3983 & 0.7902 & 0.2149 \\
\hline S17 & 70.0000 & 13.6153 & 790.4621 & 0.6827 & 0.3983 & 0.1694 & 0.0461 \\
\hline S18 & 70.0000 & 17.7289 & 790.4621 & 0.6827 & 0.3983 & 0.0404 & 0.0110 \\
\hline S19 & 85.2514 & 7.4518 & 416.0627 & 0.1587 & 0.1605 & 0.7902 & 0.0201 \\
\hline S20 & 85.2514 & 13.6153 & 416.0627 & 0.1587 & 0.1605 & 0.1694 & 0.0043 \\
\hline S21 & 85.2514 & 17.7289 & 416.0627 & 0.1587 & 0.1605 & 0.0404 & 0.0010 \\
\hline S22 & 85.2514 & 7.4518 & 609.1166 & 0.1587 & 0.4412 & 0.7902 & 0.0553 \\
\hline S23 & 85.2514 & 13.6153 & 609.1166 & 0.1587 & 0.4412 & 0.1694 & 0.0119 \\
\hline S24 & 85.2514 & 17.7289 & 609.1166 & 0.1587 & 0.4412 & 0.0404 & 0.0028 \\
\hline S25 & 85.2514 & 7.4518 & 790.4621 & 0.1587 & 0.3983 & 0.7902 & 0.0499 \\
\hline S26 & 85.2514 & 13.6153 & 790.4621 & 0.1587 & 0.3983 & 0.1694 & 0.0107 \\
\hline S27 & 85.2514 & 17.7289 & 790.4621 & 0.1587 & 0.3983 & 0.0404 & 0.0026 \\
\hline
\end{tabular}

A total of 27 scenarios can be obtained from (46). Table 2 shows the obtained scenarios and the value of the uncertain parameters and their probabilities.

Table 2. The combined scenarios and their probabilities. 


\section{Equilibrium Optimizer}

The EO is a modern optimizer which simulates models of the control volume mass balance to describe the dynamic and equilibrium states. In the EO, the concentrations denote the positions or the locations, while the particles represent the search agents of the optimizer. The particles update their location randomly around a vector known as equilibrium candidates. In addition, the generation rate is utilized for boosting the exploration and exploitation of the optimizer [31]. The mass balanced equation is described according to Equation (47) as follows:

$$
V \frac{d X}{d t}=D X_{e q}-Q X+G
$$

where $V \frac{d X}{d t}$ describes the rate of mass changing in a volume. $X$ refers to the concentration, and $V$ represents the control volume. $Q$ denotes the flow rate. $G$ denotes the mass generation rate. By integration and manipulation of Equation (47), it is formulated as follows:

$$
X=X_{e q}+\left(C_{0}-C_{e q}\right) \exp \left[-\lambda\left(t-t_{0}\right)\right]+\frac{G}{\lambda V}\left(1-\left(\exp \left[-\lambda\left(t-t_{0}\right)\right]\right)\right)
$$

where $\lambda=\left(\frac{D}{V}\right) \cdot X_{0}$ refers to the initial concentration, and $t_{0}$ is the initial start time.

The Steps of EO

Step 1: Initialization

The initial concentrations are generated randomly according to (49).

$$
X_{i}^{\text {initial }}=X_{\text {min }}+\operatorname{rand}_{i}\left(X_{\text {max }}-X_{\text {min }}\right) i=1,2, \ldots \ldots n
$$

where $X_{\max }$ is the upper boundary of the control variable, while $X_{\min }$ is its lower limit.

rand is a random value in the range [0,1]. Then, the objective function is evaluated for each obtained concentration.

Step 2: Assignment of the Equilibrium Candidates

The concentrations will be sorted according to their objective functions. The best four concentrations and their average vector represent the equilibrium candidates or the pool vector $\left(X_{\text {pool }}\right)$, which can be expressed using (50) the following:

$$
X_{\text {pool }}=\left\{X_{1}, X_{2}, X_{3}, X_{4}, X_{a v g}\right\}
$$

where

$$
X_{a v g}=\frac{X_{1}+X_{2}+X_{3}+X_{4}}{4}
$$

Step 3: Updating of the concentrations

Two vectors $(r, \lambda)$ are created randomly, and they are used to control the exponential factor $(F)$ to update the concentrations according to the following equations:

$$
F=L_{1} \operatorname{sign}(r-0.5)\left[e^{-\lambda t}-1\right]
$$

where

$$
t=\left(1-\frac{T}{T_{M a x}}\right)^{\left(L_{2} \frac{T}{T_{M a x}}\right)}
$$

where $L_{1}$ and $L_{2}$ are constant values, which equal 2 and 1 , respectively. These values are employed to adjust the exponential factor. $T_{M a x}$ is the maximum number of iterations, $T$ refers to the $T$-th iteration. It should be indicated here that $a_{1}$ is employed to control the exploration process, while $a_{2}$ is employed to control the exploitation phase o. Sign ( $\left.\mathrm{r}-0.5\right)$ can also control the exploration direction. 
Step 4: Applying the generation rate

It worth mentioning here that the generation rate is a robust approach for exploitation enhancement, and it can be defined as follows:

$$
G=G_{0} e^{-k\left(t-t_{0}\right)}
$$

where

$$
\begin{gathered}
G_{0}=G C P\left(X_{\text {pool }}-\lambda X\right) \\
G C P=\left\{\begin{aligned}
0.5 & r_{1} r_{2} \geq G P \\
0 & r_{2}<G P
\end{aligned}\right.
\end{gathered}
$$

where $r_{1}$ and $r_{2}$ refer to a random value in the range of [0,1]. GP is the probability of generation, which is utilized to control the participation probability of concentration where it is updated by the generation rate. When $G P=1$, the generation rate will not participate in the optimization process, while when $G P=0$, the generation rate will greatly participate in the process. If $G P=0$, the generation rate offers an admirable balancing between the exploration and exploitation procedures. According to the mentioned steps, the updated equation can be described using Equation (57):

$$
X=X_{\text {pool }}+\left(X-X_{\text {pool }}\right) \cdot F+\frac{G}{\lambda V}(1-F)
$$

Step 5: Adding memory saving.

The obtained solutions or concentration will be compared with the previous solution. It is worth mentioning here that the EO is proposed to solve the presented optimal planning problem, where the main advantages of the Equilibrium Optimizer lie in its ability to assign optimal solutions with higher efficiency (i.e., less computational time or fewer number of iterations) when compared with other optimization techniques, as well as its high simplicity in updating the algorithm structure and its controllability between the exploitation and exploration phases. Its related disadvantage is that it is very sensitive to its selected parameters. Figure 1 describes application of the EO for the solution of the optimal power planning problem.
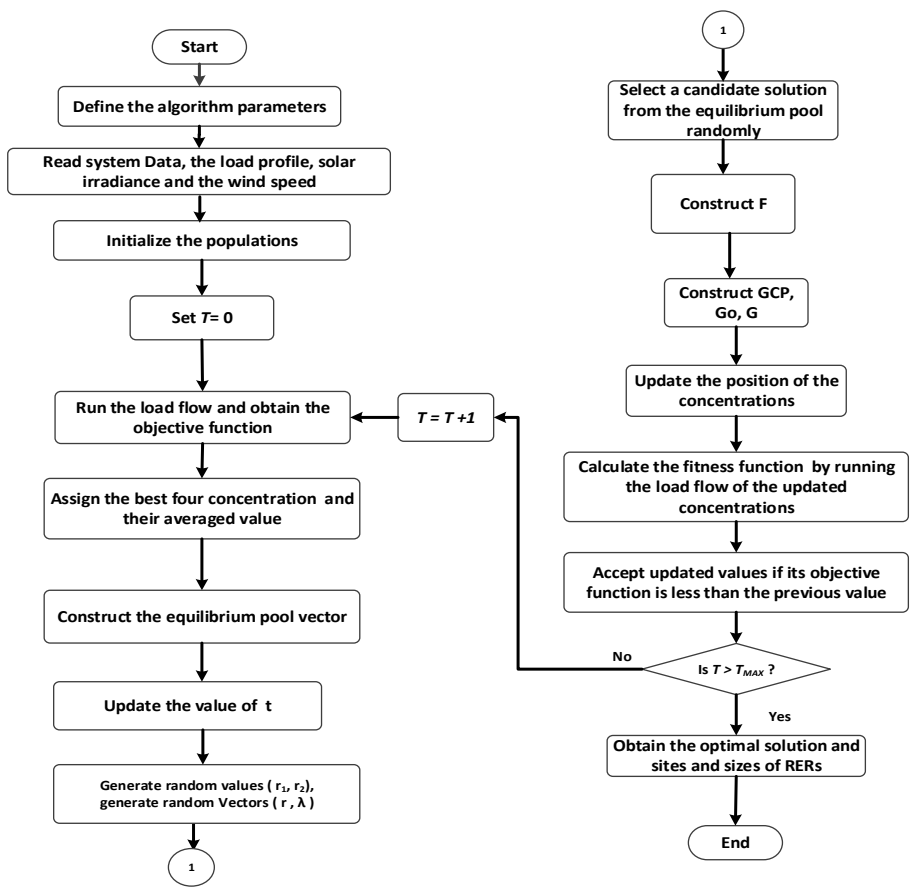

Figure 1. Application of the Equilibrium Optimizer (EO) for the optimal power planning solution. 


\section{Results and Discussion}

The optimal power planning problem has been solved by the suggested algorithm (EO), and the optimal ratings and placement of wind turbines and solar PV units are assigned under the uncertainties of renewable energy and load demand. The objective function is a multi-objective function which comprises of (1) the expected power loss, (2) the expected summation of voltage deviations, (3) the expected voltage stability index, (4) the expected cost, and (5) the expected emissions. It should be highlighted here that the value of each weight factors in (21) is selected to be 0.2 for all studied cases. The EO algorithm is implemented for IEEE 69 and 94-bus systems, and the outcomes are compared with those obtained by the Sine Cosine Algorithm (SCA) [46], Particle Swarm Optimizer (PSO) [47], and the Anti Lion Algorithm (ALO) [48]. The single line diagram of the IEEE 69 and 94-bus systems are illustrated in Figures 2 and 3, respectively. The systems data of the 69-bus and 94-bus systems are given in [49,50], respectively. The system data and the initial load flow are provided in Table 3, while the constraints of the system are given in Table 4 . The used parameters of the applied optimization techniques are tabulated in Table 5. It should be pointed out that the maximum number of search agents' and iterations or populations of the applied algorithms are selected to be the same for a fair comparison. The proposed EO technique as well as the other algorithms have been conducted on a I7-8700 CPU 3.2GHz and 24 GB RAM PC using MATLAB 2014a. The studied cases are presented below.

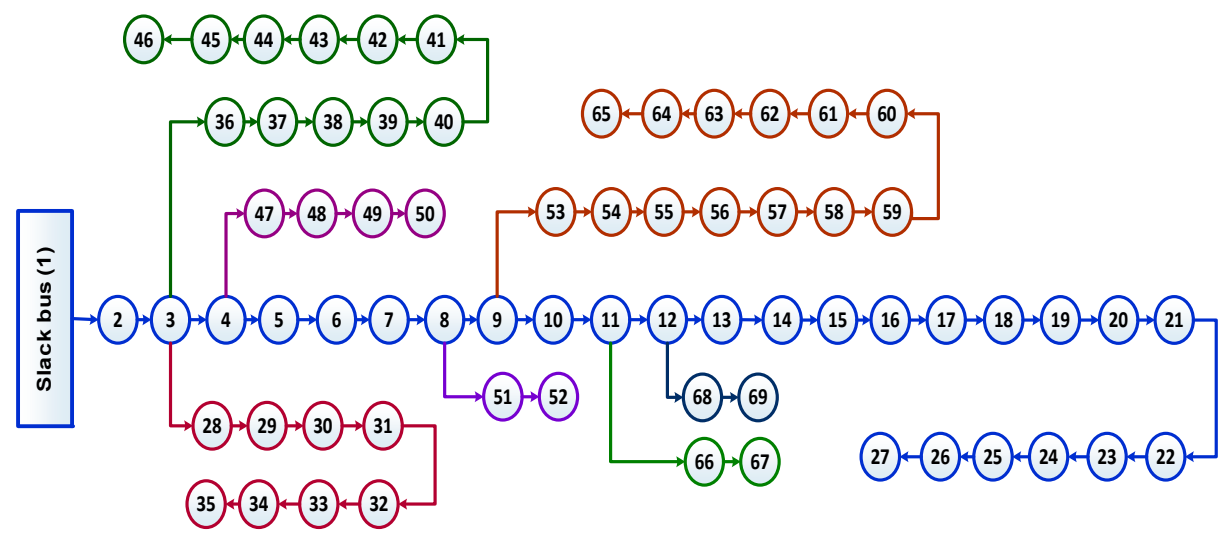

Figure 2. The IEEE 69-bus line diagram.

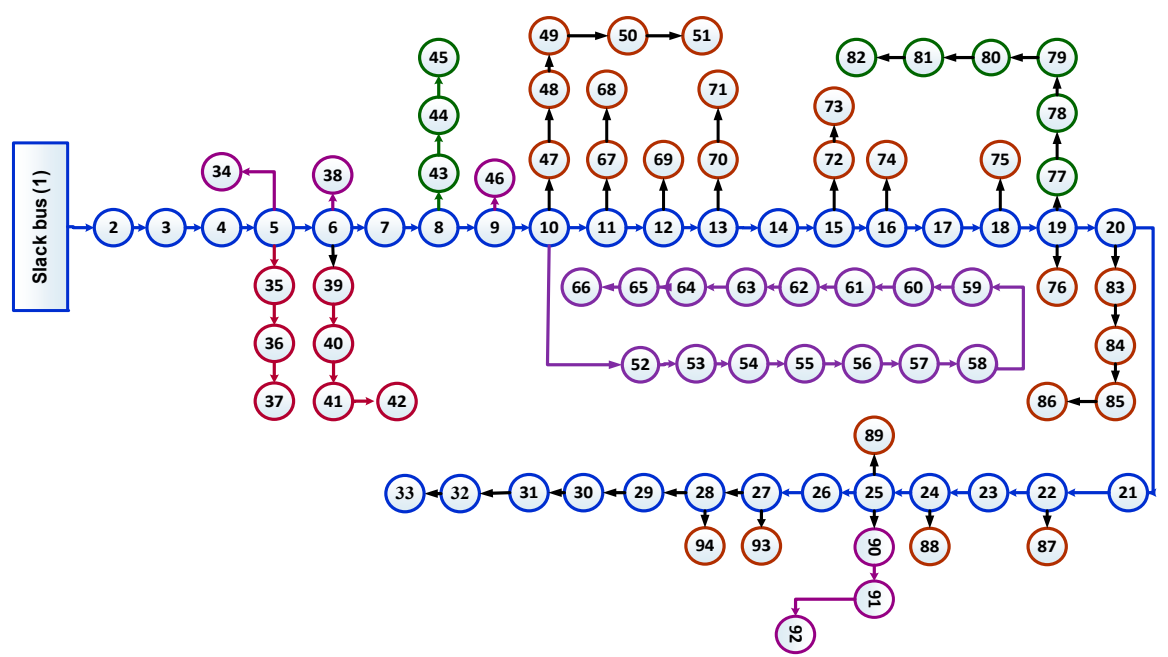

Figure 3. The IEEE 94-bus line diagram. 
Table 3. The specifications of the studied systems and initial load flow solutions.

\begin{tabular}{ccc}
\hline Item & 69-Bus & 94-Bus \\
\hline System voltage & $12.66 \mathrm{KV}$ & $15 \mathrm{KV}$ \\
$V_{\text {min }}(\mathrm{p} . \mathrm{u})$ & $0.90919 @$ bus 65 & $0.84749 @$ bus 92 \\
$V_{\text {max }}($ p.u) excluding the slack bus & $0.99997 @$ bus 2 & $0.99508 @$ bus 2 \\
Total active load demand (KW) & 3801.490 & 4797.000 \\
Total reactive load demand (KVAR) & 2694.600 & 2323.900 \\
Total active loss (KW) & 224.975 & 365.173 \\
Total reactive loss (KVAR) & 102.187 & 505.785 \\
\hline
\end{tabular}

Table 4. The system constraints.

\begin{tabular}{ll}
\hline Parameter & Value \\
\hline Voltage limits & $0.90 \leq \mathrm{V}_{\mathrm{i}} \leq 1.05 \mathrm{p.u}$ \\
PV sizing limits for the 69-bus system & $0 \leq \mathrm{P}_{\mathrm{PV}} \leq 3801.490 \mathrm{~kW}$ \\
WT sizing limits for the 69-bus system & $0 \leq \mathrm{P}_{\mathrm{WT}} \leq 3801.490 \mathrm{~kW}$ \\
Power factor limits & $0.65 \leq \mathrm{PF}_{\mathrm{i}} \leq 1$ \\
PV sizing limits for the 94-bus system & $0 \leq \mathrm{P}_{\mathrm{PV}} \leq 4797 \mathrm{~kW}$ \\
WT sizing limits for the 94-bus system & $0 \leq \mathrm{P}_{\mathrm{WT}} \leq 4797 \mathrm{~kW}$ \\
\hline
\end{tabular}

Table 5. The selected parameters of the optimization algorithms.

\begin{tabular}{ll}
\hline Algorithm & Parameter Settings \\
\hline EO & $T_{\max }=100$, Search agents No. $=25, \mathrm{~L} 1=2, \mathrm{~L} 2=1, \mathrm{GP}=0.5$ \\
PSO & $T_{\max }=100$, Search agents No. $=25$, \\
ALO & $T_{\max }=100$, Search agents No. $=25$ \\
SCA & $T_{\max }=100$, Search agents No. $=25$ \\
\hline
\end{tabular}

\subsection{The IEEE 69-Bus System}

The proposed algorithm is utilized to solve the optimal planning of the 69-bus system with optimal integration of RERs considering the uncertainties of the system. Initially, without integration of RERs, the total of the expected values of the power losses $\left(E T P_{\text {Loss }}\right)$, the total of the expected values of the voltage deviations (ETVD), the total of the expected values of the voltage stability index (ETVSI), the expected values of the total cost (ETCost), and the expected values of the emissions (ETEmission) are $144.0507 \mathrm{~kW}, 1.4014 \mathrm{p} . \mathrm{u}, 62.7261$ p.u, 2,434,700 USD, and $15.947 \times 10^{3} \mathrm{~kg} / \mathrm{MWh}$, respectively. As mentioned, in Section 3, by combining the load demand, wind speed, and solar irradiance uncertainties, 27 scenarios have been generated to model the uncertainties of the system as depicted in Table 2. By application of the EO, the optimal sites for PV and wind turbine-based DGs are at buses number 26 and 62, respectively, while the optimal rating of the PV and wind turbine-based DGs are $177.5 \mathrm{~kW}$ and $1151 \mathrm{~kW}$, respectively. Table 6 and Figure 4 provide the output power of the PV and wind turbine-based DGs for each scenario, as well as the corresponding $P_{\text {Loss }}(\mathrm{MW}), V D(\mathrm{pu}), V S I(\mathrm{pu})$, Cost (USD), and Emision (kg/MWh). As solar irradiance, wind speed, and load demand have different values in each scenario, the yielded result will also be different. At a high probability value which occurred in scenario 13, according to Table 2 the output power of the wind turbine and PV systems is $394.2 \mathrm{~kW}$ and $108.4228 \mathrm{~kW}$, respectively. Table 7 provides the expected values for each scenario with optimal integration of RERs. According to Table 7, the summation of the expected values

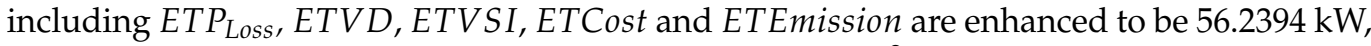
0.8816 p.u, 64.6087 p.u, 1,248,050 USD, and 4,677.936 × $10^{3} \mathrm{~kg} / \mathrm{MWh}$, respectively. 
Table 6. The output powers of renewable energy resources (RERs), the power losses, Voltage Deviations (VD), Voltage Stability Index (VSI), cost, and emission rates for each scenario of IEEE 69-bus system.

\begin{tabular}{|c|c|c|c|c|c|c|c|c|}
\hline Scenario & $P_{w}(\mathbf{k W})$ & $P 5_{s}(\mathrm{~kW})$ & $P_{\text {Loss }}(\mathrm{MW})$ & $\pi_{S}$ & $V D(p u)$ & $V S I(p u)$ & Cost (USD) & $\begin{array}{c}\text { EEmision } \\
\text { (kg/MWh) }\end{array}$ \\
\hline S1 & 394.2 & 74.0592 & 48.4097 & 0.0201 & 0.8028 & 64.8894 & $1,071,600$ & 345.9392 \\
\hline S2 & 939.9 & 74.0592 & 12.7234 & 0.0043 & 0.3889 & 66.4681 & $1,589,600$ & 723.2575 \\
\hline S3 & 1151 & 74.0592 & 12.7201 & 0.0010 & 0.318 & 67.0724 & $1,785,600$ & 860.2859 \\
\hline S4 & 394.2 & 108.4228 & 47.6489 & 0.0553 & 0.7733 & 65.0009 & $1,103,800$ & 368.7346 \\
\hline S5 & 939.9 & 108.4228 & 12.2143 & 0.0119 & 0.3597 & 66.581 & $1,621,700$ & 745.8896 \\
\hline S6 & 1151 & 108.4228 & 12.2965 & 0.0028 & 0.2924 & 67.1859 & $1,817,700$ & 882.8625 \\
\hline S7 & 394.2 & 140.7023 & 47.0604 & 0.0499 & 0.7456 & 65.1057 & $1,133,900$ & 390.0656 \\
\hline S8 & 939.9 & 140.7023 & 11.8596 & 0.0107 & 0.3323 & 66.687 & $1,651,700$ & 767.0688 \\
\hline S9 & 1151 & 140.7023 & 12.0212 & 0.0026 & 0.2684 & 67.2924 & $1,847,700$ & 903.9902 \\
\hline S10 & 394.2 & 74.0592 & 66.5655 & 0.0866 & 1.0111 & 64.119 & $1,090,700$ & 353.3142 \\
\hline S11 & 939.9 & 74.0592 & 18.8061 & 0.0186 & 0.5899 & 65.6923 & $1,612,500$ & 738.4678 \\
\hline S12 & 1151 & 74.0592 & 14.7628 & 0.0044 & 0.4346 & 66.2941 & $1,809,800$ & 878.1181 \\
\hline S13 & 394.2 & 108.4228 & 65.433 & 0.2380 & 0.9813 & 64.23 & $1,123,000$ & 376.3508 \\
\hline S14 & 939.9 & 108.4228 & 17.9418 & 0.0510 & 0.5603 & 65.8046 & $1,644,700$ & 761.3304 \\
\hline $\begin{array}{l}314 \\
\text { S15 }\end{array}$ & 1151 & 108.4228 & 13.9894 & 0.0122 & 0.4051 & 66.407 & $1,842,000$ & 900.9217 \\
\hline S16 & 394.2 & 140.7023 & 64.4987 & 0.2149 & 0.9534 & 64.3342 & $1,153,200$ & 397.9062 \\
\hline S17 & 939.9 & 140.7023 & 17.2566 & 0.0461 & 0.5327 & 65.9101 & $1,674,900$ & 782.7241 \\
\hline S18 & 1151 & 140.7023 & 13.3886 & 0.0110 & 0.3775 & 66.513 & $1,872,100$ & 922.2607 \\
\hline S19 & 394.2 & 74.0592 & 91.9413 & 0.0201 & 1.2233 & 63.3491 & $1,114,300$ & 361.2603 \\
\hline S20 & 939.9 & 74.0592 & 31.2589 & 0.0043 & 0.7942 & 64.9174 & $1,640,200$ & 754.8008 \\
\hline S21 & 1151 & 74.0592 & 22.9091 & 0.0010 & 0.6363 & 65.5169 & $1,838,900$ & 897.2459 \\
\hline S22 & 394.2 & 108.4228 & 90.4229 & 0.0553 & 1.1932 & 63.4595 & $1,146,700$ & 384.5473 \\
\hline S23 & 939.9 & 108.4228 & 30.0269 & 0.0119 & 0.7644 & 65.0292 & $1,672,500$ & 777.902 \\
\hline S24 & 1151 & 108.4228 & 21.7739 & 0.0028 & 0.6065 & 65.6292 & $1,871,200$ & 920.2843 \\
\hline $\begin{array}{l}324 \\
\text { S25 }\end{array}$ & 394.2 & 140.7023 & 89.1295 & 0.0499 & 1.165 & 63.5631 & $1,177,100$ & 406.3358 \\
\hline S26 & 939.9 & 140.7023 & 28.9996 & 0.0107 & 0.7365 & 65.1342 & $1,702,800$ & 799.5178 \\
\hline S27 & 1151 & 140.7023 & 20.8364 & 0.0026 & 0.5787 & 65.7347 & $1,901,400$ & 941.8418 \\
\hline
\end{tabular}

Table 7. The expected values for each scenario of IEEE 69-bus system.

\begin{tabular}{|c|c|c|c|c|c|c|}
\hline Scenario & $\pi_{S}$ & $\operatorname{ETP}_{\text {Loss }}(\mathrm{pu})$ & $E T V D(p u)$ & ETVSI (pu) & ETCost (USD) & $\underset{\text { (kg/MWh) }}{\text { ETEmission }}$ \\
\hline S1 & 0.0201 & 0.973 & 0.0161 & 1.3043 & 21,540 & 6.9534 \\
\hline S2 & 0.0043 & 0.0547 & 0.0017 & 0.2858 & 6840 & 3.1100 \\
\hline S3 & 0.0010 & 0.0127 & 0.0003 & 0.0671 & 1790 & 0.8603 \\
\hline S4 & 0.0553 & 2.635 & 0.0428 & 3.5946 & 61,040 & 20.3910 \\
\hline S5 & 0.0119 & 0.1453 & 0.0043 & 0.7923 & 19,300 & 8.8761 \\
\hline S6 & 0.0028 & 0.0344 & 0.0008 & 0.1881 & 5090 & 2.4720 \\
\hline S7 & 0.0499 & 2.3483 & 0.0372 & 3.2488 & 56,580 & 19.4643 \\
\hline S8 & 0.0107 & 0.1269 & 0.0036 & 0.7136 & 17,670 & 8.2076 \\
\hline S9 & 0.0026 & 0.0313 & 0.0007 & 0.175 & 4800 & 2.3504 \\
\hline S10 & 0.0866 & 5.7646 & 0.0876 & 5.5527 & 94,460 & 30.5970 \\
\hline S11 & 0.0186 & 0.3498 & 0.011 & 1.2219 & 29,990 & 13.7355 \\
\hline S12 & 0.0044 & 0.065 & 0.0019 & 0.2917 & 7960 & 3.8637 \\
\hline S13 & 0.2380 & 15.573 & 0.2335 & 15.2867 & 267,270 & 89.5715 \\
\hline S14 & 0.0510 & 0.915 & 0.0286 & 3.356 & 83,880 & 38.8278 \\
\hline S15 & 0.0122 & 0.1707 & 0.0049 & 0.8102 & 22,470 & 10.9912 \\
\hline S16 & 0.2149 & 13.8608 & 0.2049 & 13.8254 & 247,830 & 85.5101 \\
\hline S17 & 0.0461 & 0.7955 & 0.0246 & 3.0385 & 77,210 & 36.0836 \\
\hline S18 & 0.0110 & 0.1473 & 0.0042 & 0.7316 & 20,590 & 10.1449 \\
\hline S19 & 0.0201 & 1.848 & 0.0246 & 1.2733 & 22,400 & 7.2613 \\
\hline S20 & 0.0043 & 0.1344 & 0.0034 & 0.2791 & 7050 & 3.2456 \\
\hline S21 & 0.0010 & 0.0229 & 0.0006 & 0.0655 & 1840 & 0.8972 \\
\hline S22 & 0.0553 & 5.0004 & 0.066 & 3.5093 & 63,410 & 21.2655 \\
\hline S23 & 0.0119 & 0.3573 & 0.0091 & 0.7738 & 19,900 & 9.2570 \\
\hline S24 & 0.0028 & 0.061 & 0.0017 & 0.1838 & 5240 & 2.5768 \\
\hline S25 & 0.0499 & 4.4476 & 0.0581 & 3.1718 & 58,740 & 20.2762 \\
\hline S26 & 0.0107 & 0.3103 & 0.0079 & 0.6969 & 18,220 & 8.5548 \\
\hline S27 & 0.0026 & 0.0542 & 0.0015 & 0.1709 & 4940 & 2.4488 \\
\hline Summation & 1 & 56.2394 & 0.8816 & 64.6087 & $1,248,050$ & 467.7936 \\
\hline
\end{tabular}




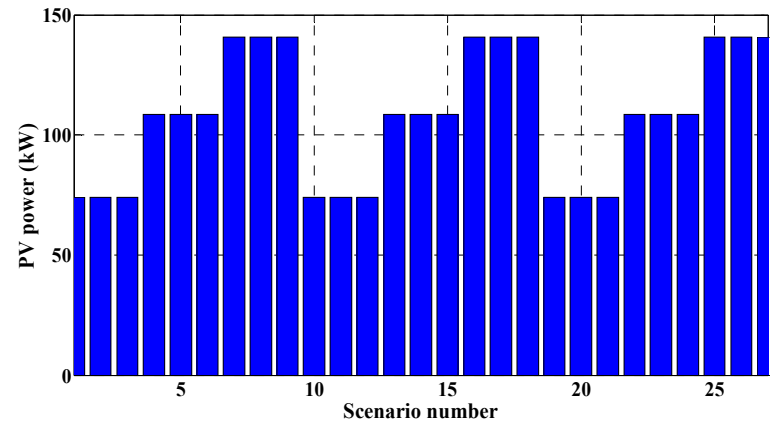

(a)

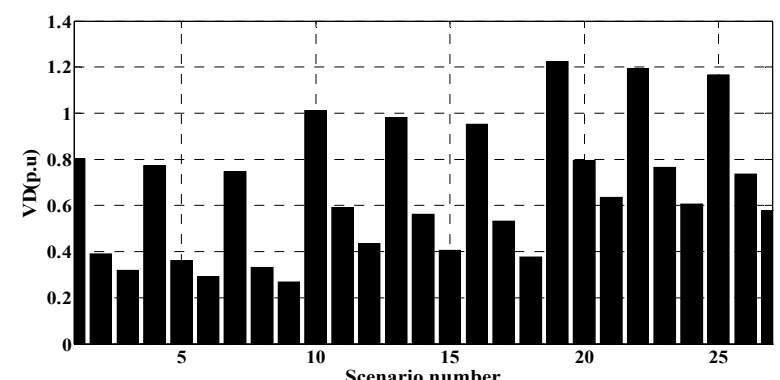

(c)

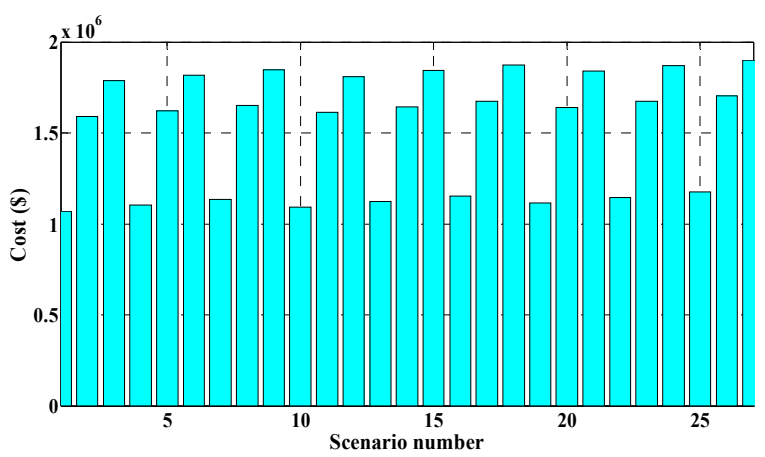

(e)

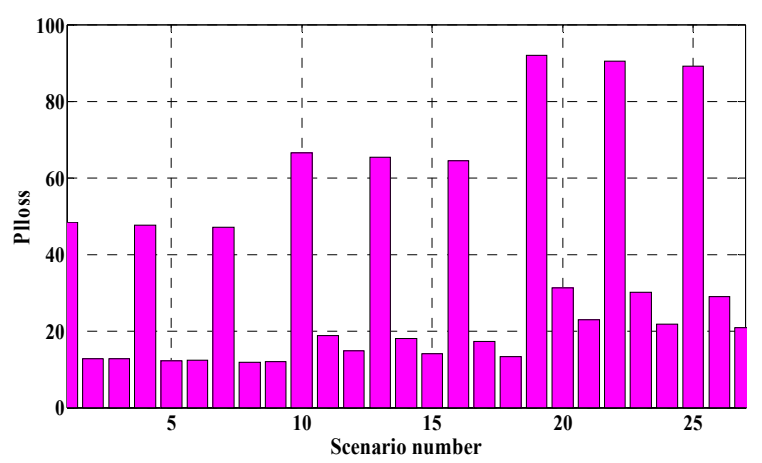

(g)

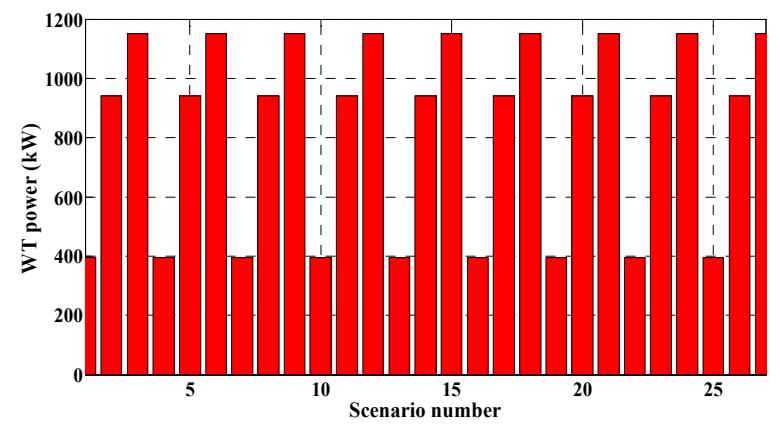

(b)

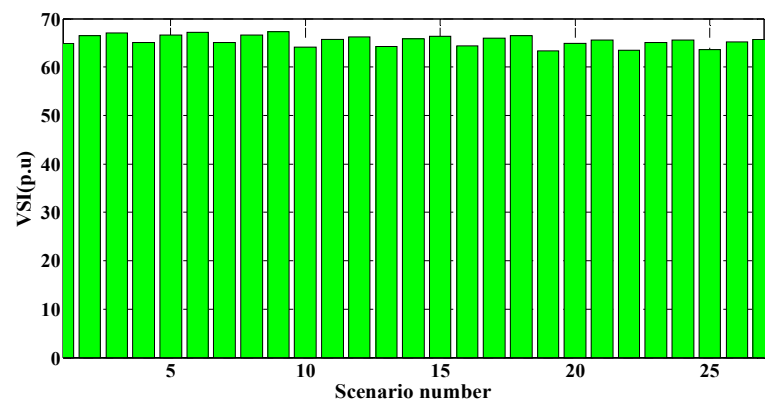

(d)

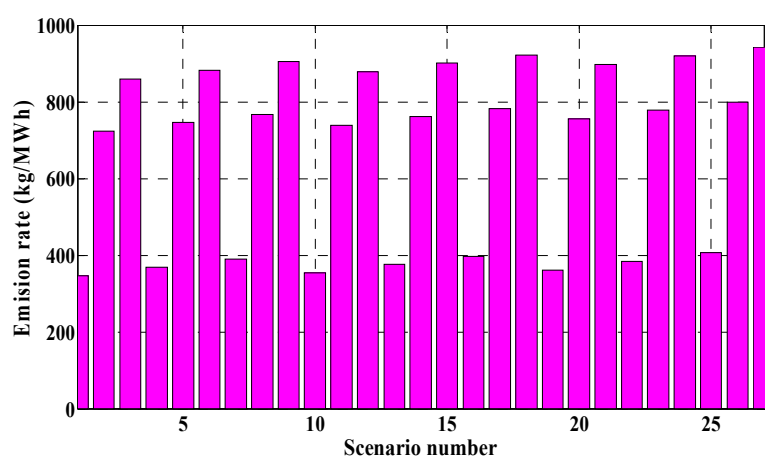

(f)

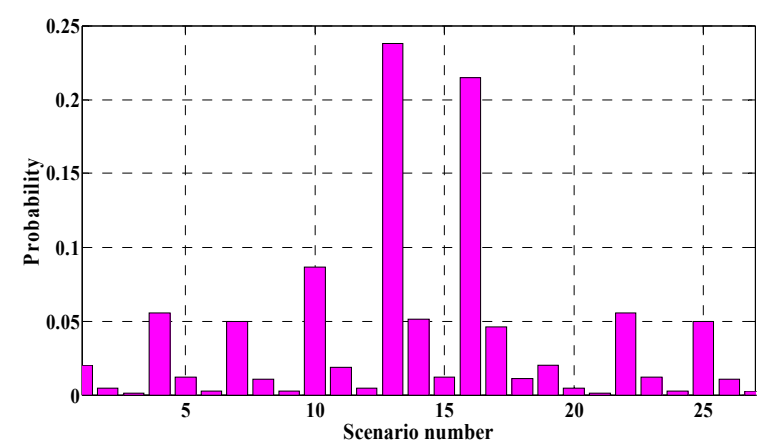

(h)

Figure 4. The outcomes for each scenario of the IEEE 69-bus system: (a) the photovoltaic (PV) power, (b) the wind turbine (WT) power, (c) the voltage deviations, (d) the voltage stability index, (e) the total cost, (f) the total emission rate, (g) the power loss, and (h) the probability. 
In other words, the enhancement in the summation of the expected values with optimal integration of the RERs including ETP $_{\text {Loss }}$ ETVD, ETVSI, ETCost, and ETEmission are $60.95 \%, 37.09 \%, 2.91 \%, 48.73 \%$, and $70.66 \%$, respectively. Figure 5 shows the voltage profile for the obtained scenarios. From this figure, it is obvious that the voltage magnitudes of all scenarios are within the allowable limits, and there is no violation which occurred. Table 8 shows a comparison of the obtained results by the application of other algorithms for the IEEE 69-bus system. Judging from Table 8, the minimum objective function has been obtained by the application of the EO compared with SCA, ALO, and PSO.

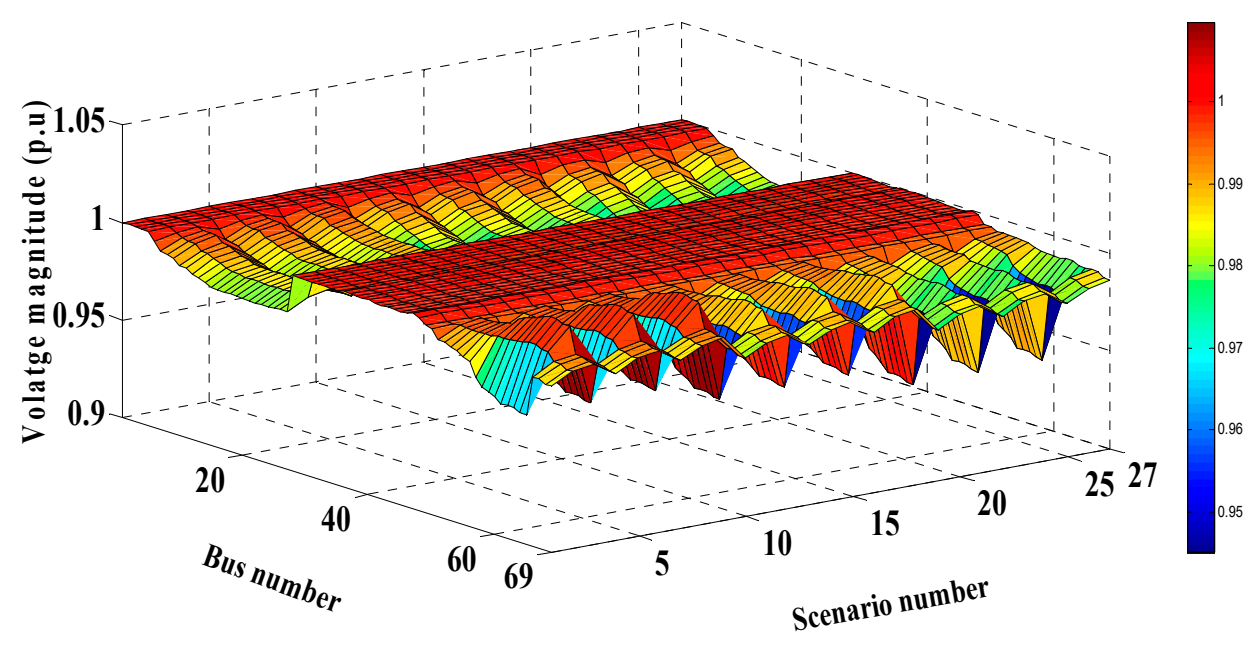

Figure 5. Voltage profile for each scenario of the 69-bus system.

Table 8. A comparison of the obtained results by the application of the investigated algorithms for the IEEE 69-bus system.

\begin{tabular}{ccccc}
\hline Algorithm & Average & Best Solution & Worst Solution & Standard Deviation \\
\hline SCA & 0.3660 & 0.3621 & 0.3851 & 0.0077 \\
PSO & 0.3934 & 0.3617 & 0.4505 & 0.0290 \\
ALO & 0.3928 & 0.3636 & 0.4147 & 0.0194 \\
EO & 0.3616 & 0.3609 & 0.3624 & 0.0006 \\
\hline
\end{tabular}

\subsection{The IEEE 94-Bus System}

The optimal planning of the 94-bus system with the optimal integration of RERs considering the uncertainties of the system has been solved by the proposed algorithm. Initially, without the integration of RERs, the total of the expected values of the power losses $\left(E T P_{\text {Loss }}\right)$, the total of the expected values of the voltage deviations $(E T V D)$, the total of the expected values of the voltage stability index (ETVSI), the expected values of the total cost (ETCost), and the expected values of the emissions (ETEmission) are $204.6913 \mathrm{~kW}, 7.2162 \mathrm{p} . \mathrm{u}$, 67.8052 p.u, 3,103,600 USD, and 20,254 × $103 \mathrm{~kg} / \mathrm{MWh}$, respectively. As referenced in Section 3 , by combining load demand, wind speed, and solar irradiance uncertainties, 27 scenarios have been generated to model the uncertainties of the system as shown in Table 2. By utilization of the EO, the optimal sites for PV and wind turbine-based DGs are at buses number 91 and 23, respectively, while the optimal rating of the PV and wind turbine-based DGs are $107.5 \mathrm{~kW}$ and $1261.6 \mathrm{~kW}$, respectively. Table 9 and Figure 6 provide the output power of the PV and wind turbine-based DGs for each scenario, as well as the corresponding $P_{\text {Loss }}(\mathrm{MW}), V D(\mathrm{pu}), V S I(\mathrm{pu}), \operatorname{Cost}(\mathrm{USD})$, and Emision (kg/MWh). As solar irradiance, wind speed, and load demand have different values in each scenario, the yielded result will also be different. At a high probability value which occurred in scenario 13 according to Table 2, the output power of the wind turbine and PV systems are $432.2 \mathrm{~kW}$ and $65.1755 \mathrm{~kW}$, respectively. 
Table 9. The output powers of RERs, the power losses, Voltage Deviations (VD), Voltage Stability Index (VSI), cost, and emission rates for each scenario of the IEEE 94-bus system.

\begin{tabular}{|c|c|c|c|c|c|c|c|c|}
\hline Scenario & $P_{w}(\mathbf{k W})$ & $P_{s}(\mathrm{~kW})$ & $P_{\text {Loss }}(\mathrm{MW})$ & $\pi_{S}$ & $V D(\mathrm{pu})$ & $V S I(p u)$ & Cost (USD) & $\begin{array}{l}\text { EEmission } \\
\text { (kg/MWh) }\end{array}$ \\
\hline S1 & 432.2 & 44.5187 & 74.0228 & 0.0201 & 4.1453 & 77.6061 & $1,144,200$ & 355.6937 \\
\hline S2 & 1030.5 & 44.5187 & 52.827 & 0.0043 & 1.5785 & 86.8996 & $1,706,500$ & 757.7621 \\
\hline S3 & 1262 & 44.5187 & 62.2786 & 0.0010 & 1.2001 & 90.5301 & $1,918,400$ & 901.8688 \\
\hline S4 & 432.2 & 65.1755 & 72.9507 & 0.0553 & 4.0964 & 77.7732 & $1,163,700$ & 369.7955 \\
\hline S5 & 1030.5 & 65.1755 & 52.801 & 0.0119 & 1.5339 & 87.0723 & $1,725,600$ & 771.1849 \\
\hline S6 & 1262 & 65.1755 & 62.5802 & 0.0028 & 1.207 & 90.705 & $1,937,500$ & 915.0791 \\
\hline S7 & 432.2 & 84.5794 & 72.0738 & 0.0499 & 4.0507 & 77.9294 & $1,182,000$ & 382.9575 \\
\hline S8 & 1030.5 & 84.5794 & 52.8868 & 0.0107 & 1.5015 & 87.2339 & $1,743,600$ & 783.7222 \\
\hline S9 & 1262 & 84.5794 & 62.9677 & 0.0026 & 1.2138 & 90.8688 & $1,955,400$ & 927.4206 \\
\hline S10 & 432.2 & 44.5187 & 112.9715 & 0.0866 & 4.987 & 74.7688 & $1,179,600$ & 367.2078 \\
\hline S11 & 1030.5 & 44.5187 & 75.2483 & 0.0186 & 2.3577 & 83.974 & $1,747,100$ & 780.0024 \\
\hline S12 & 1262 & 44.5187 & 79.4775 & 0.0044 & 1.453 & 87.5682 & $1,960,700$ & 927.4984 \\
\hline S13 & 432.2 & 65.1755 & 111.2094 & 0.2380 & 4.9359 & 74.9366 & $1,199,300$ & 381.7574 \\
\hline S14 & 1030.5 & 65.1755 & 74.644 & 0.0510 & 2.3114 & 84.1472 & $1,766,400$ & 793.8006 \\
\hline S15 & 1262 & 65.1755 & 79.2327 & 0.0122 & 1.4557 & 87.7437 & $1,979,900$ & 941.0633 \\
\hline S16 & 432.2 & 84.5794 & 109.6941 & 0.2149 & 4.8884 & 75.0935 & $1,217,800$ & 395.3338 \\
\hline S17 & 1030.5 & 84.5794 & 74.1937 & 0.0461 & 2.2683 & 84.3093 & $1,784,600$ & 806.6858 \\
\hline S18 & 1262 & 84.5794 & 79.1134 & 0.0110 & 1.4596 & 87.9079 & $1,998,000$ & 953.7337 \\
\hline S19 & 432.2 & 44.5187 & 166.2304 & 0.0201 & 5.8647 & 71.9096 & $1,224,200$ & 380.0133 \\
\hline S20 & 1030.5 & 44.5187 & 110.2486 & 0.0043 & 3.1668 & 81.0279 & $1,797,400$ & 804.6575 \\
\hline S21 & 1262 & 44.5187 & 108.7544 & 0.0010 & 2.1969 & 84.586 & $2,012,800$ & 955.8679 \\
\hline S22 & 432.2 & 65.1755 & 163.7147 & 0.0553 & 5.8113 & 72.0782 & $1,244,100$ & 395.052 \\
\hline S23 & 1030.5 & 65.1755 & 109.0211 & 0.0119 & 3.1187 & 81.2017 & $1,817,000$ & 818.8602 \\
\hline S24 & 1262 & 65.1755 & 107.9232 & 0.0028 & 2.1504 & 84.762 & $2,032,300$ & 969.8134 \\
\hline S25 & 432.2 & 84.5794 & 161.5027 & 0.0499 & 5.7616 & 72.2358 & $1,262,900$ & 409.0805 \\
\hline S26 & 1030.5 & 84.5794 & 107.9934 & 0.0107 & 3.0738 & 81.3643 & $1,835,300$ & 832.1201 \\
\hline S27 & 1262 & 84.5794 & 107.2602 & 0.0026 & 2.107 & 84.9267 & $2,050,500$ & 982.8367 \\
\hline
\end{tabular}

Table 10 provides the expected values for each scenario with the optimal integration of RERs. According to Table 10, the summation of the expected values including ETP Loss $_{1}, E T V D$, ETVSI, ETCost, and ETEmission are enhanced to be $105.6493 \mathrm{~kW}, 4.3489$ p.u, 77.0479 p.u, $1,332,680 \mathrm{USD}$, and $4774.689 \times 10^{3} \mathrm{~kg} / \mathrm{MWh}$, respectively. In other words, the enhancement in the summation of the expected values with optimal integration of the RERs including $E P_{\text {Loss }}, E V D$, ETVSI, ETCost, and EEmission are $48.38,39.73 \%, 11.99 \%, 57.06 \%$, and $76.42 \%$, respectively. Figure 7 shows the voltage profile for the obtained scenarios.

Table 10. The expected values for each scenario of the 94-bus system.

\begin{tabular}{|c|c|c|c|c|c|c|}
\hline Scenario & $\pi_{S}$ & $E T P_{\text {Loss }}(\mathrm{kW})$ & $E T V D(\mathrm{pu})$ & $\operatorname{ETVSI}(\mathrm{pu})$ & ETCost (USD) & $\begin{array}{c}\text { ETEmission } \\
\text { (kg/MWh) }\end{array}$ \\
\hline S1 & 0.0201 & 1.4879 & 0.0833 & 1.5599 & 23,000 & 71,494 \\
\hline S2 & 0.0043 & 0.2272 & 0.0068 & 0.3737 & 7340 & 32,584 \\
\hline S3 & 0.0010 & 0.0623 & 0.0012 & 0.0905 & 1920 & 9019 \\
\hline S4 & 0.0553 & 4.0342 & 0.2265 & 4.3009 & 64,350 & 204,497 \\
\hline S5 & 0.0119 & 0.6283 & 0.0183 & 1.0362 & 20,540 & 91,771 \\
\hline S6 & 0.0028 & 0.1752 & 0.0034 & 0.254 & 5430 & 25,622 \\
\hline S7 & 0.0499 & 3.5965 & 0.2021 & 3.8887 & 58,980 & 191,096 \\
\hline S8 & 0.0107 & 0.5659 & 0.0161 & 0.9334 & 18,660 & 83,858 \\
\hline S9 & 0.0026 & 0.1637 & 0.0032 & 0.2363 & 5080 & 24,113 \\
\hline S10 & 0.0866 & 9.7833 & 0.4319 & 6.475 & 102,150 & 318,002 \\
\hline S11 & 0.0186 & 1.3996 & 0.0439 & 1.5619 & 3,2500 & 145,080 \\
\hline S12 & 0.0044 & 0.3497 & 0.0064 & 0.3853 & 8630 & 40,810 \\
\hline S13 & 0.2380 & 26.4678 & 1.1748 & 17.8349 & 285,440 & 908,583 \\
\hline S14 & 0.0510 & 3.8068 & 0.1179 & 4.2915 & 90,090 & 404,838 \\
\hline S15 & 0.0122 & 0.9666 & 0.0178 & 1.0705 & 24,160 & 114,810 \\
\hline S16 & 0.2149 & 23.5733 & 1.0505 & 16.1376 & 261,710 & 849,572 \\
\hline S17 & 0.0461 & 3.4203 & 0.1046 & 3.8867 & 82,270 & 371,882 \\
\hline S18 & 0.0110 & 0.8702 & 0.0161 & 0.967 & 21,980 & 104,911 \\
\hline S19 & 0.0201 & 3.3412 & 0.1179 & 1.4454 & 24,610 & 76,383 \\
\hline S20 & 0.0043 & 0.4741 & 0.0136 & 0.3484 & 7730 & 34,600 \\
\hline S21 & 0.0010 & 0.1088 & 0.0022 & 0.0846 & 2010 & 9559 \\
\hline S22 & 0.0553 & 9.0534 & 0.3214 & 3.9859 & 68,800 & 218,464 \\
\hline S23 & 0.0119 & 1.2974 & 0.0371 & 0.9663 & 21,620 & 97,444 \\
\hline S24 & 0.0028 & 0.3022 & 0.006 & 0.2373 & 5690 & 27,155 \\
\hline S25 & 0.0499 & 8.059 & 0.2875 & 3.6046 & 63,020 & 204,131 \\
\hline S26 & 0.0107 & 1.1555 & 0.0329 & 0.8706 & 19,640 & 89,037 \\
\hline S27 & 0.0026 & 0.2789 & 0.0055 & 0.2208 & 5330 & 25,554 \\
\hline Summation & 1 & 105.6493 & 4.3489 & 77.0479 & $1,332,680$ & $4,774,869$ \\
\hline
\end{tabular}




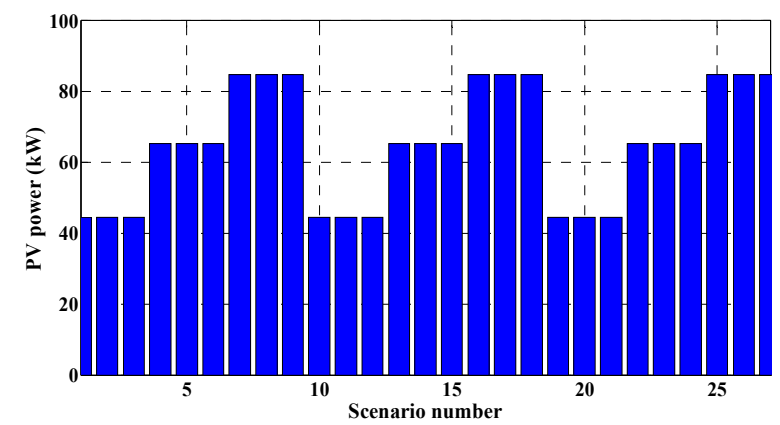

(a)

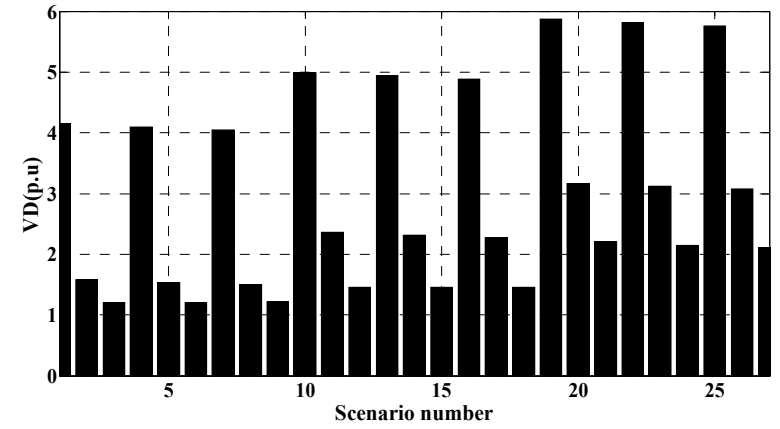

(c)

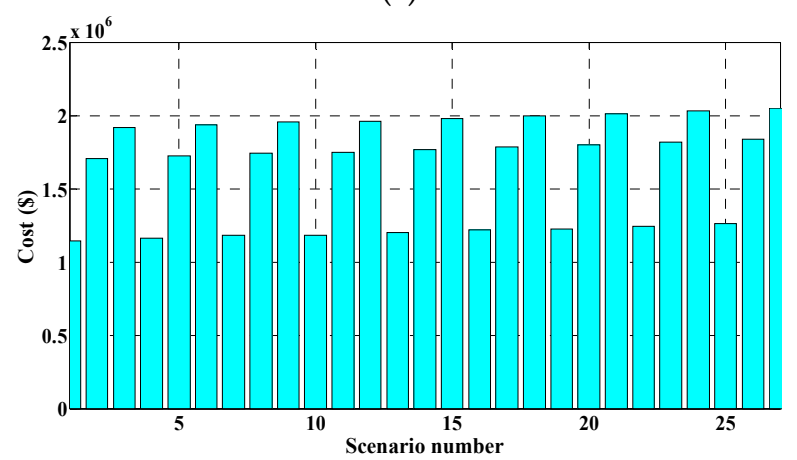

(e)

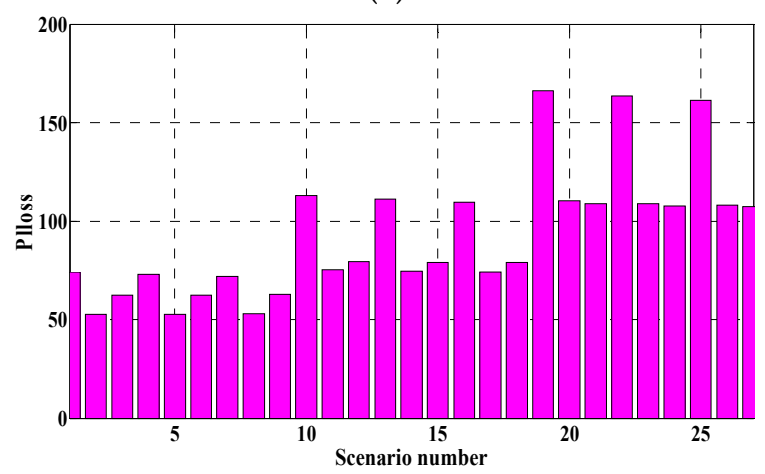

(g)

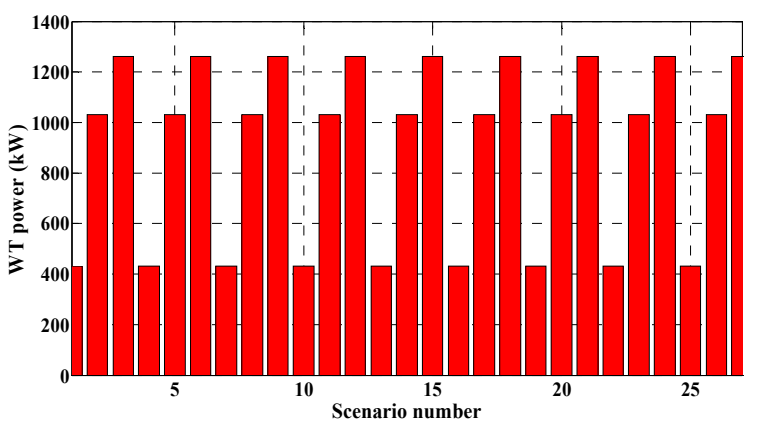

(b)

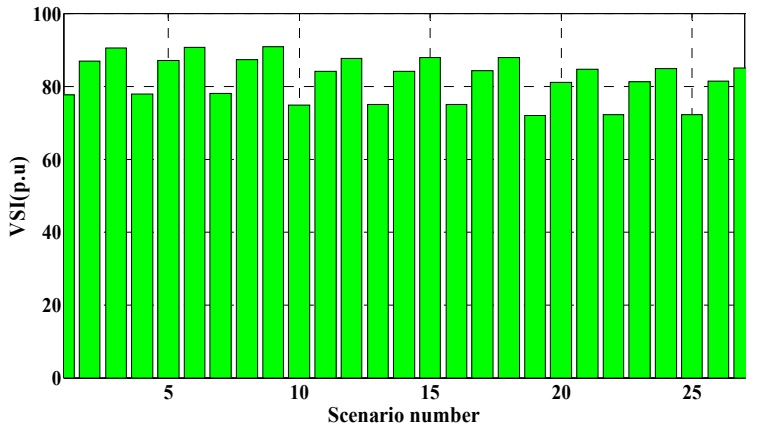

(d)

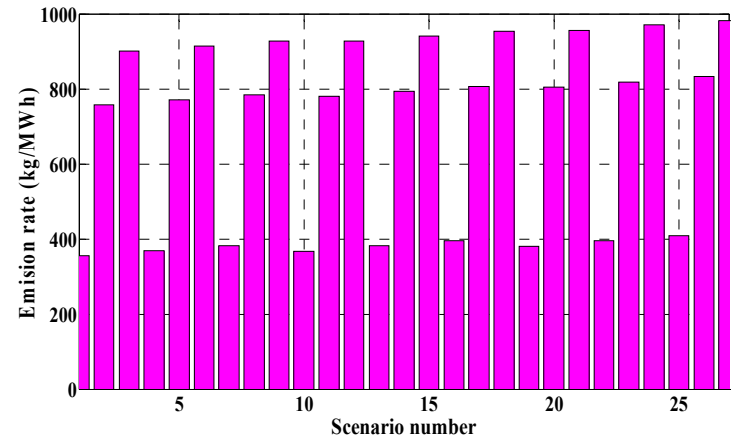

(f)

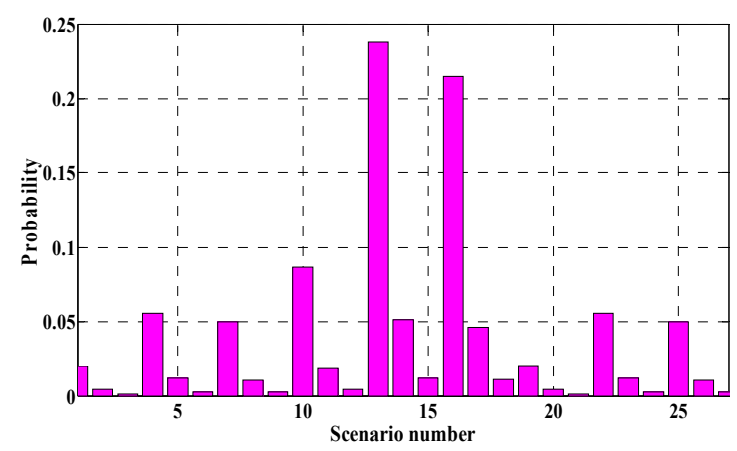

(h)

Figure 6. The outcomes for each scenario of the 94-bus system: (a) the PV power, (b) the WT power, (c) the voltage deviations, (d) the voltage stability index, (e) the total cost, (f) the total emission rate, (g) the power loss, and (h) the probability. 


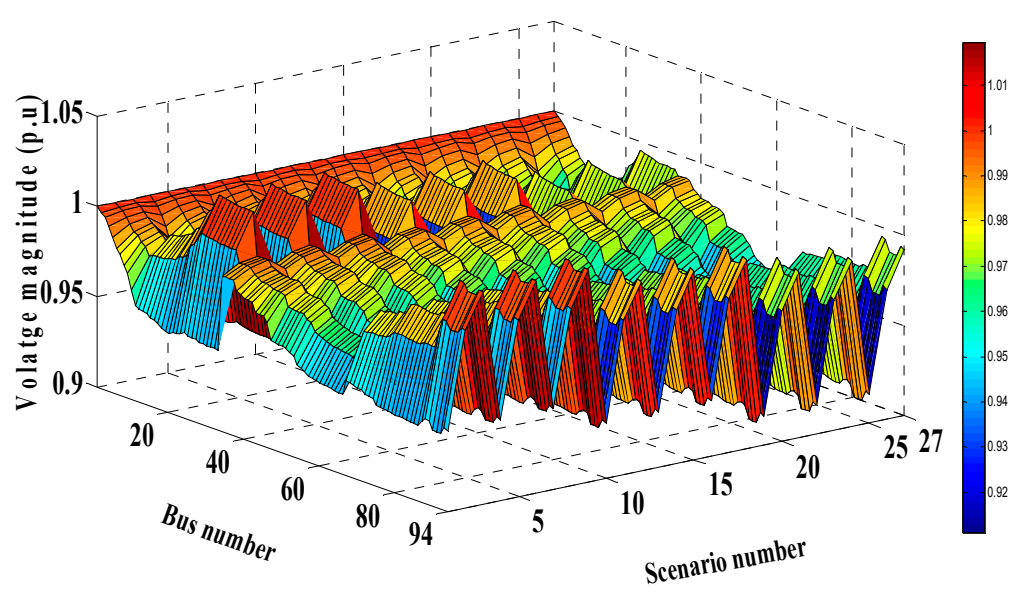

Figure 7. Voltage profile for each scenario of the 94-bus system.

From this figure, it is obvious that the voltage magnitudes of all scenarios are within the allowable limits, and no violation occurred. Table 11 shows a comparison of the obtained results by the application of other algorithms for the 94-bus system. Judging from Table 11, the minimum objective function has been obtained by the application of the EO compared with SCA, ALO, and PSO.

Table 11. A comparison of the obtained results by the application of the investigated algorithms on the 94-bus system.

\begin{tabular}{ccccc}
\hline Algorithm & Average & Best Solution & Worst Solution & SD \\
\hline SCA & 0.3546 & 0.3543 & 0.3562 & 0.0005 \\
PSO & 0.3738 & 0.3621 & 0.4141 & 0.0160 \\
ALO & 0.3898 & 0.3544 & 0.4879 & 0.0424 \\
EO & 0.3543 & 0.3535 & 0.3564 & 0.0008 \\
\hline
\end{tabular}

\section{Conclusions}

In this paper, the optimal planning for distribution systems has been solved using an efficient stochastic framework by assigning the optimal sites and sizes of solar PV and wind turbine-based DGs under uncertainties of load demands, wind speeds, and solar radiation. The proposed framework is based on application of the Equilibrium Optimizer (EO) and the scenario-based method for reducing the expected power loss, the expected system voltage deviations, the expected total cost, the expected total emissions, and maximizing the expected voltage stability. The EO has been applied for solving the allocation problem of solar PV and wind turbine-based DGs, while the scenario-based method was utilized to represent the combination the uncertainties of load demands, wind speeds, and solar radiation. The proposed technique has been implemented on an IEEE 69-bus and 94-bus practical distribution system located in Portugal, and the obtained results were compared with those obtained by SCA, PSO, and ALO. The obtain results verified the following:

- The effectiveness of the proposed framework for solving the optimal planning problem for distribution systems.

- The superiority of the EO for assigning the optimal placement and sizes of the DGs compared to SCA, PSO, and ALO techniques.

- The inclusion of solar PV and wind turbine-based DGs using the proposed method in the IEEE 69-bus system can reduce the expected power losses, voltage deviations, cost, and emissions rate and enhance the voltage stability compared to the base case by $60.95 \%, 37.09 \%, 2.91 \%, 70.66 \%$, and $48.73 \%$, respectively.

- The inclusion of solar PV and wind turbine-based DGs using the proposed method in a 94-bus system can reduce the expected power losses, voltage deviations, cost, and 
emissions rate and enhance the voltage stability compared to the base case by $48.38 \%$, $39.73 \%, 57.06 \%, 76.42 \%$, and $11.99 \%$, respectively.

Author Contributions: Conceptualization, A.R., M.E., S.K., H.H.A.; data curation, A.Y.A.; formal analysis, A.R. and M.E.; resources, A.Y.A.; methodology, S.K.; software, A.R., M.E. and S.K.; supervision, A.Y.A., H.H.A.; validation, A.R. and S.K.; visualization, A.Y.A.; writing- original draft, A.R. and M.E.; writing-review and editing, S.K., H.H.A. and A.Y.A. All authors together organized and refined the manuscript in the present form. All authors have approved the final version of the submitted paper. All authors have read and agreed to the published version of the manuscript.

Funding: H. Haes Alhelou was supported in part by Science Foundation Ireland (SFI) under the SFI Strategic Partnership Programme Grant Number SFI/15/SPP/E3125 and additional funding provided by the UCD Energy Institute. The opinions, findings, and conclusions or recommendations expressed in this material are those of the authors and do not necessarily reflect the views of the Science Foundation Ireland.

Institutional Review Board Statement: Not applicable.

Informed Consent Statement: Not applicable.

Data Availability Statement: Not applicable.

Conflicts of Interest: The authors declare no conflict of interest.

\section{Abbreviations}

$\begin{array}{ll}\text { Acronyms } & \\ \text { DGs } & \text { Distributed Generators } \\ \text { DSs } & \text { Distribution Systems } \\ \text { PV } & \text { Photovoltaic } \\ \text { WT } & \text { Wind Turbine } \\ \text { RERs } & \text { Renewable Energy Resources } \\ \text { PDF } & \text { Probability Distribution Function } \\ \text { RDN } & \text { Radial Distribution Network } \\ \text { EO } & \text { Equilibrium Optimizer } \\ \text { SCA } & \text { Sine Cosine Algorithm } \\ \text { ALO } & \text { Ant-Lion Optimizer } \\ \text { PSO } & \text { Particle Swarm Optimization } \\ \text { IAGA } & \text { Improved Adaptive Genetic Algorithm } \\ \text { MFO } & \text { Moth Flame Optimization } \\ \text { GA } & \text { Genetic-Algorithm } \\ \text { GA-MCS } & \text { Genetic-Algorithm with Monte Carlo simulation } \\ \text { CSA } & \text { Cuckoo Search Algorithm } \\ \text { CSO-MCS } & \text { Crisscross Optimization Algorithm and Monte Carlo Simulation } \\ \text { IALO } & \text { Improved Antlion Optimization Algorithm } \\ \text { SGA } & \text { Specialized Genetic Algorithm } \\ \text { ACO } & \text { Ant Colony Optimizer } \\ \text { MDEA } & \text { Modified Differential Evolution Algorithm } \\ \text { SOA } & \text { Seeker Optimization Algorithm } \\ \text { Indices and Sets } & \\ P_{l o s s} & \text { Loss power } \\ P_{\text {Total_Loss }} & \text { The total active power loss } \\ E T P_{\text {Loss }} & \text { Expected Total Loss Power } \\ R_{k, k+1} & \text { The resistance of the line between buses } k \text { and } k+1, \\ P_{k} & \text { Reactive powers } \\ Q_{k} & \\ P_{L} & \end{array}$




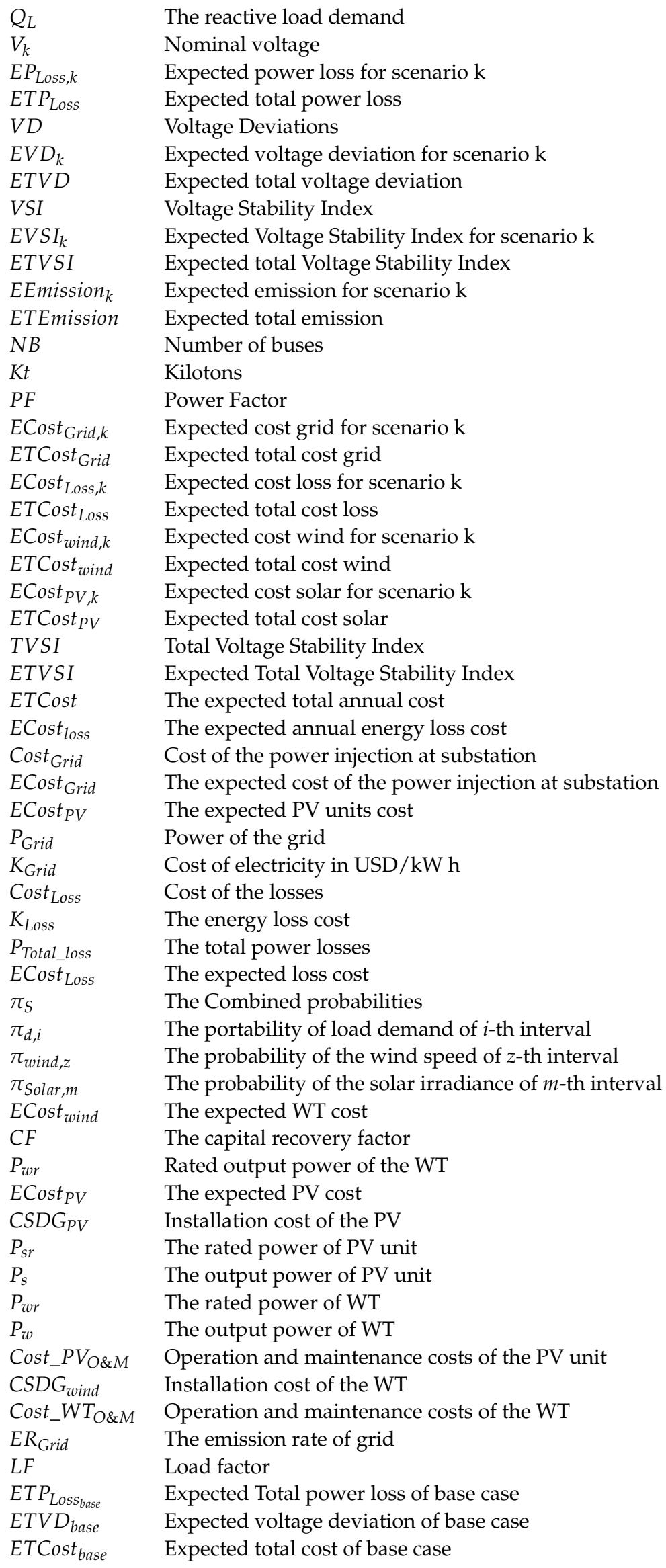




\begin{tabular}{|c|c|}
\hline ETEmission $_{\text {base }}$ & Expected emission rate of base case \\
\hline$f_{d}$ & The normal PDF of load demand \\
\hline$f_{v}$ & The Weibull PDF of wind speed \\
\hline$f_{G}$ & The Beta PDF of solar irradiance \\
\hline$v_{\omega i}$ & The cut in wind speed of WT \\
\hline$v_{\omega r}$ & The rated wind speed of WT \\
\hline$v_{\omega o}$ & The cut out wind speed of WT \\
\hline$k, c$ & Shape and scale parameters of Weibull function \\
\hline$\sigma_{d}$ & The standard deviation of the load demand \\
\hline$\mu_{d}$ & The mean deviation of the load demand \\
\hline$\alpha_{1}, \alpha_{2}, \alpha_{3}, \propto_{4}, \alpha_{5}$ & The weight factors \\
\hline$\rho$ & Rate of interest on DG capital investment \\
\hline$T_{\max }$ & Number of iterations \\
\hline$N P$ & Lifetime of the PV unit or the WT \\
\hline$N T$ & Number of branches \\
\hline$I_{\max }$ & Maximum Allowable current in branches \\
\hline$Q_{W T}$ & Injected reactive power by wind turbine \\
\hline NWT & Number of wind turbine \\
\hline$V_{\min }$ & Minimum allowable voltage limit \\
\hline$V_{\max }$ & Maximum allowable voltage limit \\
\hline$Q_{\text {Grid }}$ & Reactive power injected at slack bus \\
\hline$N P V$ & Number of PV units \\
\hline$P_{d, i}^{\max }$ & The maximum limit of the selected interval $i$ \\
\hline$P_{d, i}^{\min }$ & The minimum limit of the selected interval $i$ \\
\hline$v_{z}^{\max }$ & The ending point of wind speed's interval at $z$-th scenario \\
\hline$v_{z}^{\min }$ & The starting point of wind speed's interval at $z$-th scenario \\
\hline$G_{m}^{\max }$ & The ending point of solar irradiance's interval at $m$-th scenario \\
\hline$G_{m}^{\min }$ & The starting point of solar irradiance's interval at $m$-th scenario \\
\hline
\end{tabular}

Solar Irradiance

A certain irradiance point

Standard environment solar irradiance $(1000 \mathrm{~W} / \mathrm{m} 2)$

Voltage of the $n$-th bus

Gamma function

Parameters of the beta PDF

Mean deviation of the solar irradiance for each time segment

Multi-objective function

The objective function representing the normalized active total power losses The objective function representing the normalized total voltage deviations The objective function representing the normalized voltage stability index The objective function representing the normalized total cost The objective function representing the normalized total emission

\section{References}

1. Ganguly, S.; Sahoo, N.; Das, D. Recent advances on power distribution system planning: A state-of-the-art survey. Energy Syst. 2013, 4, 165-193. [CrossRef]

2. Sims, R.E.; Rogner, H.-H.; Gregory, K. Carbon emission and mitigation cost comparisons between fossil fuel, nuclear and renewable energy resources for electricity generation. Energy Policy 2003, 31, 1315-1326. [CrossRef]

3. Ehsan, A.; Yang, Q. Active distribution system reinforcement planning with EV charging stations-Part I: Uncertainty modeling and problem formulation. IEEE Trans. Sustain. Energy 2019, 11, 970-978. [CrossRef]

4. Cervantes, J.; Choobineh, F. Optimal sizing of a nonutility-scale solar power system and its battery storage. Appl. Energy 2018, 216, 105-115. [CrossRef]

5. Lai, C.S.; Jia, Y.; Lai, L.L.; Xu, Z.; McCulloch, M.D.; Wong, K.P. A comprehensive review on large-scale photovoltaic system with applications of electrical energy storage. Renew. Sustain. Energy Rev. 2017, 78, 439-451. [CrossRef] 
6. Xavier, G.A.; Martins, J.H.; Monteiro, P.M.d.B.; Diniz, A.S.A.C.; Diniz, A.C. Simulation of distributed generation with photovoltaic microgrids-Case study in Brazil. Energies 2015, 8, 4003-4023. [CrossRef]

7. Weckx, S.; D'hulst, R.; Driesen, J. Locational pricing to mitigate voltage problems caused by high PV penetration. Energies 2015, 8, 4607-4628. [CrossRef]

8. Georgilakis, P.S.; Hatziargyriou, N.D. A review of power distribution planning in the modern power systems era: Models, methods and future research. Electr. Power Syst. Res. 2015, 121, 89-100. [CrossRef]

9. Gao, Y.; Liu, J.; Yang, J.; Liang, H.; Zhang, J. Multi-objective planning of multi-type distributed generation considering timing characteristics and environmental benefits. Energies 2014, 7, 6242-6257. [CrossRef]

10. El-Khattam, W.; Hegazy, Y.; Salama, M. An integrated distributed generation optimization model for distribution system planning. IEEE Trans. Power Syst. 2005, 20, 1158-1165. [CrossRef]

11. Liu, Z.; Wen, F.; Ledwich, G. Optimal siting and sizing of distributed generators in distribution systems considering uncertainties. IEEE Trans. Power Deliv. 2011, 26, 2541-2551. [CrossRef]

12. Shaaban, M.F.; El-Saadany, E. Accommodating high penetrations of PEVs and renewable DG considering uncertainties in distribution systems. IEEE Trans. Power Syst. 2013, 29, 259-270. [CrossRef]

13. Zeng, B.; Zhang, J.; Zhang, Y.; Yang, X.; Dong, J.; Liu, W. Active distribution system planning for low-carbon objective using cuckoo search algorithm. J. Electr. Eng. Technol. 2014, 9, 433-440. [CrossRef]

14. Peng, X.; Lin, L.; Zheng, W.; Liu, Y. Crisscross optimization algorithm and Monte Carlo simulation for solving optimal distributed generation allocation problem. Energies 2015, 8, 13641-13659. [CrossRef]

15. Esmaeili, M.; Sedighizadeh, M.; Esmaili, M. Multi-objective optimal reconfiguration and DG (Distributed Generation) power allocation in distribution networks using Big Bang-Big Crunch algorithm considering load uncertainty. Energy 2016, 103, 86-99. [CrossRef]

16. Santos, S.F.; Fitiwi, D.Z.; Bizuayehu, A.W.; Shafie-Khah, M.; Asensio, M.; Contreras, J.; Cabrita, C.M.P.; Catalao, J.P. Novel multi-stage stochastic DG investment planning with recourse. IEEE Trans. Sustain. Energy 2016, 8, 164-178. [CrossRef]

17. Kroposki, B.; Sen, P.K.; Malmedal, K. Optimum sizing and placement of distributed and renewable energy sources in electric power distribution systems. IEEE Trans. Ind. Appl. 2013, 49, 2741-2752. [CrossRef]

18. Baghaee, H.; Mirsalim, M.; Gharehpetian, G.; Talebi, H. Reliability/cost-based multi-objective Pareto optimal design of standalone wind/PV/FC generation microgrid system. Energy 2016, 115, 1022-1041. [CrossRef]

19. Saric, M.; Hivziefendic, J.; Konjic, T.; Ktena, A. Distributed generation allocation considering uncertainties. Int. Trans. Electr. Energy Syst. 2018, 28, e2585. [CrossRef]

20. Zhao, B.; Guo, C.; Cao, Y. A multiagent-based particle swarm optimization approach for optimal reactive power dispatch. IEEE Trans. Power Syst. 2005, 20, 1070-1078. [CrossRef]

21. Abdel-Fatah, S.; Ebeed, M.; Kamel, S. Optimal Reactive Power Dispatch Using Modified Sine Cosine Algorithm. In Proceedings of the 2019 International Conference on Innovative Trends in Computer Engineering (ITCE), Aswan, Egypt, 2-4 February 2019; pp. 510-514.

22. Sulaiman, M.; Rashid, M.M.; Aliman, O.; Mohamed, M.; Ahmad, A.; Bakar, M. Loss minimisation by optimal reactive power dispatch using cuckoo search algorithm. In Proceedings of the 3rd IET International Conference on Clean Energy and Technology (CEAT) 2014, Kuching, Malaysia, 24-26 November 2014.

23. Heidari, A.A.; Abbaspour, R.A.; Jordehi, A.R. Gaussian bare-bones water cycle algorithm for optimal reactive power dispatch in electrical power systems. Appl. Soft Comput. 2017, 57, 657-671. [CrossRef]

24. Li, Z.; Cao, Y.; Dai, L.V.; Yang, X.; Nguyen, T.T. Finding solutions for optimal reactive power dispatch problem by a novel improved antlion optimization algorithm. Energies 2019, 12, 2968. [CrossRef]

25. Villa-Acevedo, W.M.; López-Lezama, J.M.; Valencia-Velásquez, J.A. A novel constraint handling approach for the optimal reactive power dispatch problem. Energies 2018, 11, 2352. [CrossRef]

26. Abou El-Ela, A.; Kinawy, A.; El-Sehiemy, R.; Mouwafi, M. Optimal reactive power dispatch using ant colony optimization algorithm. Electr. Eng. 2011, 93, 103-116. [CrossRef]

27. Sakr, W.S.; El-Sehiemy, R.A.; Azmy, A.M. Adaptive differential evolution algorithm for efficient reactive power management. Appl. Soft Comput. 2017, 53, 336-351. [CrossRef]

28. Khazali, A.; Kalantar, M. Optimal reactive power dispatch based on harmony search algorithm. Int. J. Electr. Power Energy Syst. 2011, 33, 684-692. [CrossRef]

29. Dai, C.; Chen, W.; Zhu, Y.; Zhang, X. Seeker optimization algorithm for optimal reactive power dispatch. IEEE Trans. Power Syst. 2009, 24, 1218-1231.

30. Mandal, B.; Roy, P.K. Optimal reactive power dispatch using quasi-oppositional teaching learning based optimization. Int. J. Electr. Power Energy Syst. 2013, 53, 123-134. [CrossRef]

31. Faramarzi, A.; Heidarinejad, M.; Stephens, B.; Mirjalili, S. Equilibrium optimizer: A novel optimization algorithm. Knowl.-Based Syst. 2020, 191, 105190. [CrossRef]

32. Ramadan, A.; Ebeed, M.; Kamel, S.; Nasrat, L. Optimal power flow for distribution systems with uncertainty. In Uncertainties in Modern Power Systems; Elsvier: Amsterdam, The Netherlands, 2020; pp. 145-162. 
33. Bastawy, M.; Ebeed, M.; Rashad, A.; Alghamdi, A.S.; Kamel, S. Micro-Grid Dynamic Economic Dispatch with Renewable Energy Resources Using Equilibrium Optimizer. In Proceedings of the 2020 IEEE Electric Power and Energy Conference (EPEC), Edmonton, AB, Canada, 9-10 November 2020; pp. 1-5.

34. Özkaya, H.; Yıldız, M.; Yıldız, A.R.; Bureerat, S.; Yıldız, B.S.; Sait, S.M. The equilibrium optimization algorithm and the response surface-based metamodel for optimal structural design of vehicle components. Mater. Test. 2020, 62, 492-496. [CrossRef]

35. Abdel-Basset, M.; Mohamed, R.; Mirjalili, S.; Chakrabortty, R.K.; Ryan, M.J. Solar photovoltaic parameter estimation using an improved equilibrium optimizer. Sol. Energy 2020, 209, 694-708. [CrossRef]

36. Gampa, S.R.; Das, D. Optimum placement and sizing of DGs considering average hourly variations of load. Int. J. Electr. Power Energy Syst. 2015, 66, 25-40. [CrossRef]

37. Soroudi, A.; Aien, M.; Ehsan, M. A probabilistic modeling of photo voltaic modules and wind power generation impact on distribution networks. IEEE Syst. J. 2011, 6, 254-259. [CrossRef]

38. Mohseni-Bonab, S.M.; Rabiee, A. Optimal reactive power dispatch: A review, and a new stochastic voltage stability constrained multi-objective model at the presence of uncertain wind power generation. IET Gener. Transm. Distrib. 2017, 11, 815-829. [CrossRef]

39. Ebeed, M.; Alhejji, A.; Kamel, S.; Jurado, F. Solving the Optimal Reactive Power Dispatch Using Marine Predators Algorithm Considering the Uncertainties in Load and Wind-Solar Generation Systems. Energies 2020, 13, 4316. [CrossRef]

40. Hetzer, J.; David, C.Y.; Bhattarai, K. An economic dispatch model incorporating wind power. IEEE Trans. Energy Convers. 2008, 23, 603-611. [CrossRef]

41. Biswas, P.P.; Suganthan, P.N.; Mallipeddi, R.; Amaratunga, G.A.J. Optimal reactive power dispatch with uncertainties in load demand and renewable energy sources adopting scenario-based approach. Appl. Soft Comput. 2019, 75, 616-632. [CrossRef]

42. Atwa, Y.; El-Saadany, E.; Salama, M.; Seethapathy, R. Optimal renewable resources mix for distribution system energy loss minimization. IEEE Trans. Power Syst. 2009, 25, 360-370. [CrossRef]

43. Salameh, Z.M.; Borowy, B.S.; Amin, A.R. Photovoltaic module-site matching based on the capacity factors. IEEE Trans. Energy Convers. 1995, 10, 326-332. [CrossRef]

44. Liang, R.-H.; Liao, J.-H. A fuzzy-optimization approach for generation scheduling with wind and solar energy systems. IEEE Trans. Power Syst. 2007, 22, 1665-1674. [CrossRef]

45. Reddy, S.S.; Bijwe, P.; Abhyankar, A.R. Real-time economic dispatch considering renewable power generation variability and uncertainty over scheduling period. IEEE Syst. J. 2014, 9, 1440-1451. [CrossRef]

46. Mirjalili, S. SCA: A sine cosine algorithm for solving optimization problems. Knowl.-Based Syst. 2016, 96, 120-133. [CrossRef]

47. Eberhart, R.; Kennedy, J. A New Optimizer Using Particle Swarm Theory. In Proceedings of the Sixth International Symposium on Micro Machine and Human Science (MHS'95), Nagoya, Japan, 4-6 October 1995; pp. 39-43.

48. Mirjalili, S. The ant lion optimizer. Adv. Eng. Softw. 2015, 83, 80-98. [CrossRef]

49. Chandramohan, S.; Atturulu, N.; Devi, R.K.; Venkatesh, B. Operating cost minimization of a radial distribution system in a deregulated electricity market through reconfiguration using NSGA method. Int. J. Electr. Power Energy Syst. 2010, 32, 126-132. [CrossRef]

50. Pires, D.F.; Antunes, C.H.; Martins, A.G. NSGA-II with local search for a multi-objective reactive power compensation problem. Int. J. Electr. Power Energy Syst. 2012, 43, 313-324. [CrossRef] 